\title{
The Coastal Observing System for Northern and Arctic Seas (COSYNA)
}

\author{
Burkard Baschek $^{1}$, Friedhelm Schroeder ${ }^{1}$, Holger Brix ${ }^{1}$, Rolf Riethmüller ${ }^{1}$, Thomas H. Badewien ${ }^{2}$, \\ Gisbert Breitbach $^{1}$, Bernd Brügge ${ }^{3}$, Franciscus Colijn ${ }^{1}$, Roland Doerffer ${ }^{1}$, Christiane Eschenbach ${ }^{1}$, Jana Friedrich ${ }^{1}$, \\ Philipp Fischer ${ }^{4}$, Stefan Garthe ${ }^{5}$, Jochen Horstmann ${ }^{1}$, Hajo Krasemann ${ }^{1}$, Katja Metfies ${ }^{4}$, Lucas Merckelbach ${ }^{1}$, \\ Nino Ohle ${ }^{6}$, Wilhelm Petersen ${ }^{1}$, Daniel Pröfrock ${ }^{1}$, Rüdiger Röttgers ${ }^{1}$, Michael Schlüter ${ }^{4}$, Jan Schulz ${ }^{2}$, \\ Johannes Schulz-Stellenfleth ${ }^{1}$, Emil Stanev ${ }^{1}$, Joanna Staneva ${ }^{1}$, Christian Winter ${ }^{7}$, Kai Wirtz ${ }^{1}$, Jochen Wollschläger ${ }^{1}$, \\ Oliver Zielinski ${ }^{2}$, and Friedwart Ziemer ${ }^{1}$ \\ ${ }^{1}$ Institute of Coastal Research, Helmholtz-Zentrum Geesthacht, Geesthacht, Germany \\ ${ }^{2}$ Institute for Chemistry and Biology of the Marine Environment, University of Oldenburg, Oldenburg, Germany \\ ${ }^{3}$ Federal Maritime and Hydrographic Agency, Hamburg, Germany \\ ${ }^{4}$ Alfred Wegener Institute, Helmholtz Center for Polar and Marine Research, Center for Polar and Marine Research, \\ Bremerhaven, Germany \\ ${ }^{5}$ Research and Technology Centre (FTZ), University of Kiel, Büsum, Germany \\ ${ }^{6}$ Hamburg Port Authority, Hamburg, Germany \\ ${ }^{7}$ MARUM, Center for Marine Environmental Sciences, Bremen University, Bremen, Germany
}

Correspondence to: Burkard Baschek (burkard.baschek@hzg.de)

Received: 15 May 2016 - Discussion started: 30 May 2016

Revised: 29 November 2016 - Accepted: 10 February 2017 - Published: 10 May 2017

\begin{abstract}
The Coastal Observing System for Northern and Arctic Seas (COSYNA) was established in order to better understand the complex interdisciplinary processes of northern seas and the Arctic coasts in a changing environment. Particular focus is given to the German Bight in the North Sea as a prime example of a heavily used coastal area, and Svalbard as an example of an Arctic coast that is under strong pressure due to global change.

The COSYNA automated observing and modelling system is designed to monitor real-time conditions and provide short-term forecasts, data, and data products to help assess the impact of anthropogenically induced change. Observations are carried out by combining satellite and radar remote sensing with various in situ platforms. Novel sensors, instruments, and algorithms are developed to further improve the understanding of the interdisciplinary interactions between physics, biogeochemistry, and the ecology of coastal seas. New modelling and data assimilation techniques are used to integrate observations and models in a quasi-operational system providing descriptions and forecasts of key hydrographic variables. Data and data products are publicly available free
\end{abstract}

of charge and in real time. They are used by multiple interest groups in science, agencies, politics, industry, and the public.

\section{Introduction}

A large part of humanity lives near the coasts and depends on the coastal oceans. At the same time, global problems such as climate change, sea level rise, or ocean acidification influence the ecosystems and communities along the coasts in particular. Shelf seas host unique ecosystems and provide essential sources for life in the ocean and the bordering land, while regions like the North Sea are heavily used for a multitude of human activities, from tourism and ship traffic to the exploitation and exploration of food resources, energy, and raw materials. Shelf seas are also heavily influenced by terrestrial processes due to continuous influx of natural and anthropogenic material from river systems and the atmosphere. They therefore act as important interfaces for global material cycles, for example through the uptake, emission, and transport of carbon compounds. 
Understanding coastal systems is therefore of a high value, not only from a scientific point of view, but also due to its societal value. Coastal research has, however, long been hampered by the effort involved in investigating the highly complex coastal systems, the diversity of disciplines and institutions involved, and the difficulties in obtaining long-term and high-resolution, consistent measurements.

Current observations in the North Sea reveal substantial changes in biogeochemistry and food webs accompanied by the occurrence of new and the disappearance of established species (Gollasch et al., 2009; Buschbaum et al., 2012). The causes of these shifts are only partially known. Changes in physical quantities (e.g. temperature, wind) as well as anthropogenic influences (e.g. pollution, over-fishing, invasive species) most probably act as major drivers (Emeis et al., 2015). In the Arctic, the thawing of permafrost has started to cause coastal erosion and an increase in greenhouse gas emissions (IPCC, 2014). These examples highlight the sensitivity and dynamic behaviour of such complex systems that are still barely understood and insufficiently documented and monitored.

Recent advances in technology enable the use of remotely controlled automated measurements and the development of "intelligent" integrated systems that combine measurements and numerical modelling to create a synoptic view of coastal systems. The Coastal Observing System for Northern and Arctic Seas (COSYNA) has been established to demonstrate the feasibility of this idea for shallow, coastal areas. COSYNA focuses on the complex interdisciplinary processes of the German Bight in the North Sea and the Arctic coast near Svalbard, to assess the impact of anthropogenic changes, and to provide a scientific infrastructure. The focus regions have been chosen because they are ideal test beds in terms of natural variability and processes, human use and change, as well as accessibility.

The principal objective of observations, instrument development, and modelling is to improve our understanding of the interdisciplinary interactions between physical, biogeochemical, and ecological processes in coastal seas, to investigate how they can be best described at present, and how they will evolve in the future. To this end, COSYNA combines its measurement capabilities in the German Bight in a network that is designed to expand beyond individual platforms, areas, campaigns, and quantities to generate a holistic view of the entire coastal system by analysing the multitude of measurements taking into consideration the combination of different data sources as well as integrating them into model analyses.

In COSYNA, data and knowledge tools are developed and provided to be of use for multiple interest groups in industry, agencies, politics, environmental protection, or the public. These data and products are publicly available free of charge and can be used to support national monitoring authorities to comply, for example, with the requirements of the European Water Framework Directive and the Marine Strat- egy Framework Directive. The coastal observatory involves national and international contributions to international programmes, such as the coastal module of the Global Ocean Observing System (coastal GOOS), the European Ocean Observing System (EOOS as supported by EuroGOOS), the Global Earth Observations System of Systems (GEOSS), Marine Geological and Biological Habitat Mapping (GEOHAB), and the COPERNICUS Marine Environment Monitoring Service (CMEMS).

COSYNA is coordinated by the Helmholtz-Zentrum Geesthacht (HZG), Germany, and has been jointly developed, implemented, and operated with 10 other German partner institutions (see Table 1).

The present Ocean Science and Biogeochemistry interjournal special issue, "COSYNA: integrating observations and modeling to understand coastal systems", collects contributions highlighting various aspects of the complex observing system. This article provides an overview of COSYNA, its observational and modelling approach, as well as the diverse associated scientific studies and activities. It aims at connecting the articles in the special issue to previously published results from COSYNA. To this end, we will first describe the focus regions (Sect. 2), objectives (Sect. 3), and the international context of COSYNA (Sect. 4), before giving an overview of the observations (Sect. 5), sensor and instrument development (Sect. 6), as well as modelling and data assimilation activities (Sect. 7). Data, data products, and outreach activities are then described (Sects. 8 and 9) before a brief outlook on future activities is given (Sect. 10).

\section{Coastal focus regions}

The focus regions of COSYNA, the German Bight of the North Sea and the Arctic coast at Svalbard, are representative of two extremes in the broad spectrum of northern and Arctic coasts. The German Bight is one of the most intensely used coastal seas worldwide, with often opposing interests of economy, nature conservation, and recreation. Arctic seas and coasts are among the areas most affected by and vulnerable to global warming. For a recent assessment of impacts of climate change on the North Sea region, see NOSCCA (2016).

\subsection{The German Bight}

The German Bight (Fig. 1) is located in the south-eastern corner of the North Sea, a temperate, semi-enclosed shelf sea. Sündermann et al. (1999) define its seaward boundaries at $6^{\circ} 30^{\prime} \mathrm{E}$ and $55^{\circ} 00^{\prime} \mathrm{N}$. The German Bight is relatively shallow, with water depths of generally less than $40 \mathrm{~m}$. The main topographical features are the glacially formed Elbe River valley that spreads out to the north-west and a chain of barrier islands along the Dutch, German, and Danish North Sea coast. The islands protect the major part of the Wadden Sea, 
Table 1. COSYNA partners.

\begin{tabular}{ll}
\hline Helmholtz-Zentrum Geesthacht (co-ordination) & HZG \\
Alfred Wegener Institute, Helmholtz Centre for Polar and Marine Research & AWI \\
Center for Marine Environmental Sciences at Bremen University & MARUM \\
Institute for Chemistry and Biology of the Marine Environment at the University of Oldenburg & ICBM \\
Research and Technology Centre at the University of Kiel & FTZ \\
German Federal Maritime and Hydrographic Agency & BSH \\
Center for Earth System Research and Sustainability & CEN \\
Hamburg Port Authority & HPA \\
Lower Saxony State Department for Waterway, Coastal and Nature Conservation & NLWKN \\
Schleswig-Holstein's Agency for Coastal Defence, National Parks, and Marine Conservation & LKN \\
German Federal Waterways Engineering and Research Institute & BAW \\
\hline
\end{tabular}

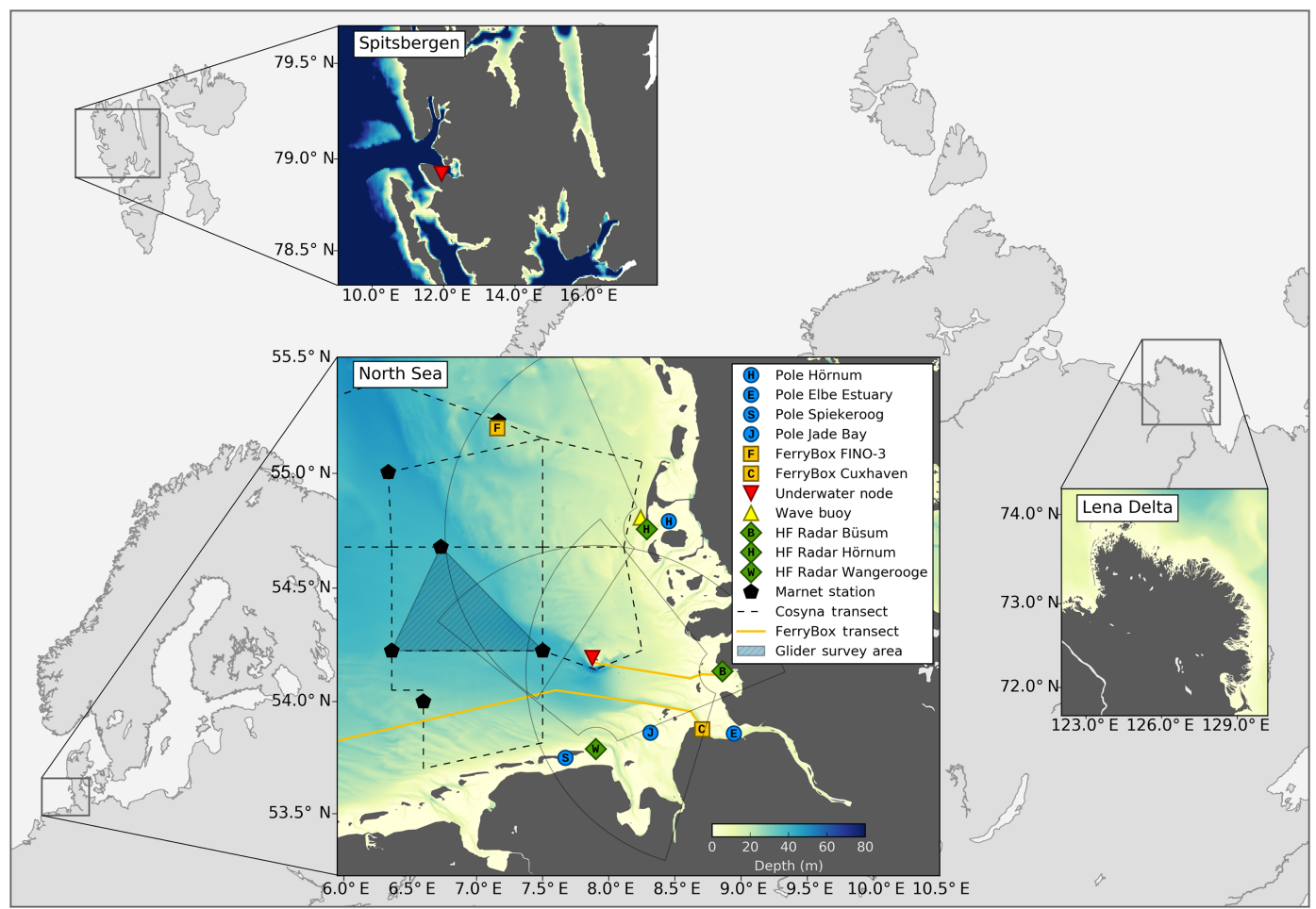

Figure 1. Map showing the pre-operational components of the COSYNA coastal observing system.

the largest unbroken system of intertidal sand and mud flats in the world.

The North Sea is characterised by the transition from oceanic to brackish water with variable freshwater input at the coasts. Physical drivers such as wind, sea surface temperature (SST), or tides control the natural variability in circulation and exchange processes with the open sea and the coastal fringe boundaries over a broad range of temporal and spatial scales (Schulz et al., 1999; Sündermann et al., 1999; Emeis et al., 2015; NOSCCA, 2016).

Strong tidal currents and intermittent strong wind events form a regime of high kinetic and turbulent energy with significant bed-water column exchange in the North Sea. Westerly winds typically prevail in the North Sea, but variations exist and southerlies and easterlies may produce secondary circulation patterns (Otto et al., 1990). The currents are dominated by the M2 lunar tidal component that enters the North Sea from the north and moves as a Kelvin wave cyclonically through the North Sea (Otto et al., 1990; Howarth, 2001). Strong tidal currents in the channels connecting the Wadden Sea with the German Bight drive an intense exchange and a net import of suspended particulate matter and nutrients into the Wadden Sea (Burchard et al., 2008; Staneva et al., 2009; van Beusekom et al., 2012) and sustain its muddy component and the high productivity of the intertidal mud flats (Postma, 1984; van Beusekom et al., 1999; van Beusekom and de Jonge, 2002; Colijn and de Jonge, 1984). The tides thus cause a complex pattern of mixing conditions just off the 


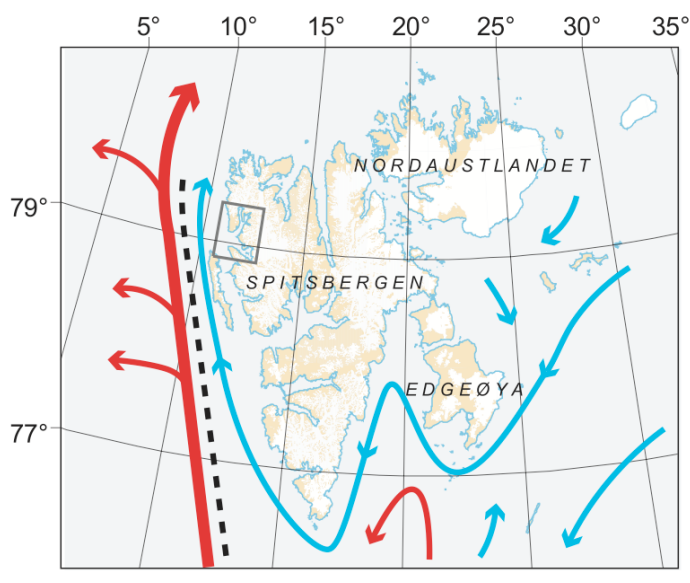

Figure 2. Spitsbergen with Kongsfjord (small rectangle) at the western coast of Svalbard. Arrows indicate the warmer Atlantic water masses (red) from the West Spitsbergen Current and colder less saline Arctic water (blue) from the East Spitsbergen Current (Cottier et al., 2005).

barrier islands and the mouths of the estuaries of the rivers Elbe, Weser, and Ems.

Global and local anthropogenic impacts overlay and interfere with these natural forcings. The global increase in $\mathrm{CO}_{2}$ concentrations led to a long-term increase in SST that accelerated to $0.08^{\circ} \mathrm{C} \mathrm{yr}^{-1}$ in the last decade (Loewe, 2009), while the average annual sea level rise reached $1.6 \mathrm{~mm} \mathrm{yr}^{-1}$ for the last 110 years (Wahl et al., 2013), and the average pH decreased from 8.08 to 8.01 in the years 1970 to 2006 (Lorkowski et al., 2012).

The North Sea is surrounded by densely populated, highly industrialised countries and is directly affected by multiple, often conflicting uses. One of the densest ship traffic lines worldwide crosses the German Bight and demands regular dredging of shipping channels and harbour basins. The Wadden Sea region, a UNESCO World Natural Heritage Site since 2009, is exposed to an import of pollutants and nutrients from land. The high biomass production caused by the latter resulted in the identification of the entire German Bight as a problem area by the OSPAR commission (OSPAR, 2008). Overfishing with bottom trawls impacts benthic invertebrate communities and leads to a decrease in biomass and species richness of fish communities (Emeis et al., 2015). As the latest development, the massive construction of offshore wind farms - underway or planned - is likely to have a significant impact on marine mammals (Koschinky et al., 2003) and seabirds (Garthe and Hüppop, 2004; M. Busch et al., 2013), but possibly also mixing (Lass et al., 2008; Ludewig, 2015; Carpenter et al., 2016) and nutrient transport.

\subsection{The Arctic coast}

While Spitsbergen $\left(79^{\circ} \mathrm{N}\right)$ is geographically classified as fully Arctic, it is significantly influenced by Arctic and At-

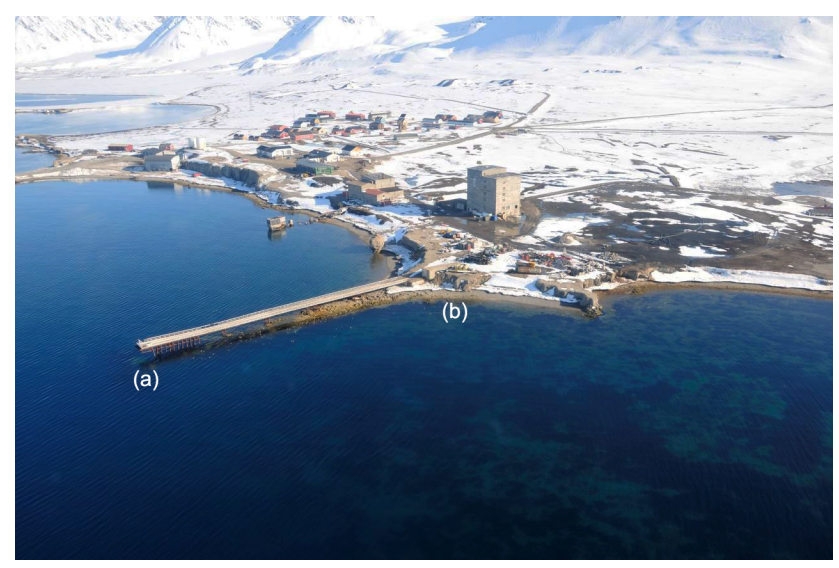

Figure 3. Research village NyÅlesund. The Spitsbergen Underwater-Node is located about $30 \mathrm{~m}$ in front of the Old Pier (a). The control station is located at the base of the Old Pier on land (b).

lantic water masses from the Fram Strait (Fig. 2; Hop et al., 2002). Due to an increased advection rate of warmer Atlantic water masses in the fjord systems over the last decade, the first signs of an overall warming in the fjords have been observed, with a decrease in seasonal ice coverage (Stroeve et al., 2007) and significant changes throughout the food web (Hegseth and Tverberg, 2013; Van de Poll et al., 2016; Willis et al., 2006; Brand and Fischer, 2016).

The $20 \mathrm{~km}$ long Kongsfjord is located at the western coast of Svalbard and opens to a shelf system in a westerly direction. It has no sill and shares the outlet to the Atlantic with the more northern Krossfjord (Cottier et al., 2005). From this outlet, an underwater canyon runs through the shelf to the continental edge, establishing a connection to the deeper water masses of the West Spitsbergen Current off the shelf. Complex mixing processes between the Arctic shelf water masses, the Atlantic deep water masses, and the highly seasonal freshwater runoff from the inner part of the fjord result in strong environmental gradients from the inner parts of the fjords to its mouth (Svendsen et al., 2002). These gradients and their short- and long-term variability directly influence the pelagic and benthic realms of the fjord and the local food web (Stempniewicz et al., 2007). Due to the condensed temporal and spatial patterns of Atlantic and polar realms in a single fjord system, as well as the observed increase in mean water temperatures, the retreat of glaciers, and decrease in sea ice coverage over the last decades, the Kongsfjord ecosystem (Fig. 2) became an international focal point of climate change research.

The first research station addressing the Kongsfjord ecosystems was built by the Norsk Polar Institute in NyÅlesund (Fig. 3) at $78^{\circ} 55^{\prime} \mathrm{N}, 11^{\circ} 56^{\prime} \mathrm{E}$ in 1970 . Since then, more than 15 nations have operated their own research stations in this northernmost year-round inhabited research village of 
the world, including German-French research station AWIPEV (www.awipev.eu).

Even in Kongsfjord with its ideal and year-round available research infrastructure, most field research has been done in summer (Fischer et al., 2017) and only very little is known about the several month long polar winter with its prevailing darkness. The winter months are, however, essential for life cycles, the reproduction of many species (Fischer et al., 2017), and hence for the entire ecosystem (Hop et al., 2012). It is COSYNA's aim to help close this observational gap, providing year-round observations in this polar fjord system.

COSYNA activities also comprise remote sensing techniques that have been proved and tested in the North Sea to coastal waters in the Lena Delta, Siberia, for the quantification of suspended matter and chlorophyll as well as in situ measurements of inherent optical properties (Örek et al., 2013). The Lena Delta covers $32000 \mathrm{~km}^{2}$ and discharges freshwater from a catchment area of $2400000 \mathrm{~km}^{2}$ into the Arctic Ocean.

\section{Objectives and benefits}

Complex, highly interdisciplinary natural processes characterise the North Sea across several timescales and lengthscales. It is COSYNA's goal to help disentangle natural processes and anthropogenic impact in this region by combining consistent long-term time series at representative locations with process-oriented high-resolution observations. Numerical models of various resolutions are used to provide a context for observations ranging from the turbulent to basin-wide spatial scales. Observations are integrated into models using data assimilation techniques for resolutions, timescales, and quantities where such integration is possible and useful. It has therefore been COSYNA's approach to build an integrated observing system that is geared towards high flexibility and can be used on a variety of scales and problems that are of scientific or societal interest.

Routine observations of key variables and data assimilation techniques are employed to improve model performance for hindcasts, nowcasts, and short-term forecasts. The implementation of such a system achieves several objectives: it bridges spatial and temporal scales, while it establishes a backdrop against which key processes, such as exchange processes between the North Sea and Wadden Sea, the impact of extreme events, biological productivity variations, and the influences of e.g. offshore wind farm construction, can be investigated. The extensive development of offshore wind farms, for instance, requires sound environmental statistics and improved forecasts for planning and operation, while their influence on hydrodynamics, let alone biogeochemistry or biology, of the North Sea is still poorly understood.

The benefits of the COSYNA system are expected to be manifold. It contributes to technology development of key sensors and infrastructure, data interpretation algorithms such as for satellites and HF radar, as well as to modelling and data assimilation techniques suitable for operational use and monitoring. These developments and the creation of products of interest for various user groups contribute to the sciences while also benefitting society, e.g. by supplying coastal and seafloor observations of the North Sea in support of the European framework strategies and directives towards the goal of achieving a "good environmental status" of the marine environment.

As for the dissemination of data and products, COSYNA's objective is to make them available free of charge to the broadest possible audience in near-real time, while ensuring high quality standards and rigorous monitoring of data quality. Additional quality controls taking long-term perspectives into account are to be performed on an ongoing basis, ultimately resulting in data publications.

\section{International context}

With the initiation of the permanent Global Ocean Observing System - GOOS (Intergovernmental Oceanographic Commission, 1993) - and stepwise implementation of its many separate observing systems, new concepts regarding the worldwide systematic and sustained observation of the oceans have been put in place. Considering the role of coastal areas in ecological communities and their exposure to massive human utilisation, a GOOS coastal module was proposed to provide a basis for extended predictability of the coastal environment in both model and observations (Intergovernmental Oceanographic Commission, 1997). Awareness of the multitude of societal benefits (ABARE, 2006; https://ioos.noaa.gov/about/ societal-benefits/) stimulated considerable investment in the worldwide implementation of integrated coastal ocean observatories (ICOOS).

In Europe, EuroGOOS (http://eurogoos.eu) is the pan-European GRA that co-ordinates six regional operational systems (ROOSes), such as the North West Shelf Operational Oceanographic System (NOOS, http://eurogoos.eu/roos/north-west-european-shelf-

operational). In addition to providing operational oceanographic services and carrying out marine research, EuroGOOS puts considerable effort into unlocking fragmented and hidden marine data and making them openly available. Its data play a key role in the development of the European Marine Observation and Data Network (EMODnet) data portals (http://www.emodnet.eu). EMODnet is designed to cover all European coastal waters. The European ROOSes feed data into EMODnet either directly or through SeaDataNet (Schaap and Lowry, 2010; http://www.seadatanet.org/) and the Copernicus Marine Environment Monitoring Service (CMEMS, http://marine.copernicus.eu).

COSYNA contributes through the Helmholtz-Zentrum Geesthacht (HZG), as a EuroGOOS member, to the defi- 
Table 2. Standard COSYNA observables.

\begin{tabular}{ll}
\hline Platform & Parameter \\
\hline Meteorology & pressure, temperature, global radiation, and wind vector \\
Physical oceanography & $\begin{array}{l}\text { pressure, temperature, salinity, current, wave height, and direction } \\
\text { optical turbidity, total suspended matter concentration, } \\
\text { Biogeochemistry } \\
\text { chlorophyll } a \text { concentration, and dissolved oxygen }\end{array}$ \\
\hline
\end{tabular}

nition and implementation of operational services for nearcoast, shallow ocean waters. Based on the FerryBox project funded by the EU in 2002-2005, HZG is co-chairing the FerryBox EuroGOOS Task Team (http://www.ferrybox.org). Via NOOS, the FerryBox data are fed into the EMODnet portals, while COSYNA's high-frequency radar data are delivered directly to the EMODnet Physics data portal and the glider data to the CMEMS data server.

\section{Observations}

The COSYNA observation network was designed to cover spatial scales ranging from a tidal catchment area in the Wadden Sea to the southern North Sea (Fig. 1). An additional observing station was installed at the western coast of Svalbard. Nearly all platforms deliver a set of COSYNA standard observables comprising key meteorological, oceanographic, and biogeochemical bulk parameters (Table 2). Tables 3 and 4 provide a comprehensive overview of the COSYNA platforms.

Four stationary systems were installed on poles placed in three tidal basins of East Frisia and one in the North Frisian Wadden Sea. They provide highly resolved COSYNA standard parameters (see Table 2) and allow the integration of energy and matter budgets over the sampled catchment areas. An additional pole and a stationary FerryBox monitor the exchange between the German Bight and the Elbe River as its main tributary.

To estimate transports across the northern cross section of the German Bight, a FerryBox was installed on the FINO3 (Forschungsplattformen in Nord- und Ostsee) wind-turbine research platform. Upstream of it, along the mean transport pathway in the German Bight, the FINO1 platform is located at the site of a station belonging to the Marine Environmental Monitoring Network in the North Sea and Baltic Sea (MARNET) operated by the German Federal Maritime and Hydrographic Agency (BSH). In general, MARNET complements the fixed COSYNA platforms (Table 3) towards the offshore regions of the German exclusive economic zone (EEZ). FerryBox systems operating on several ships of opportunity extend the COSYNA network to the North Sea scale, with several regular routes.

To provide a good spatial coverage, remote sensing with high-frequency (HF) radar and satellites is used. Two HF radar arrays are installed at the North Frisian coast and one at the East Frisian coast with a nearly rectangular viewing angle to the other two systems. This configuration allows the determination of horizontal surface current vectors over most of the German Bight. The surface concentrations of total suspended matter, chlorophyll $a$, and yellow substances, "Gelbstoff", were obtained from 2003 to 2012 with MERIS (Medium Resolution Imaging Spectrometer) onboard ENVISAT, followed by MODIS (Moderate Resolution Imaging Spectroradiometer).

To go beyond the limitations in power and data transmission rates that most COSYNA platforms face, two COSYNA Underwater-Node Systems were developed and installed. They are pilots towards long-term observations of parameters beyond the COSYNA standard observables, such as optical systems for non-invasive determination of plankton or fish populations and their behaviour. The underwater node off the island of Helgoland is the first installation in a shallow water environment worldwide subject to strong wave forces. At Svalbard, the underwater node allows year-round observations under the sea ice under harsh environmental conditions. To explore physical and biogeochemical processes at the sediment-water interface over longer periods of time in high detail, three lander systems were developed that can be connected to the Underwater-Node Systems for longer operations.

Observations of the vertical distribution of variables over most of the water column were achieved with two alternating gliders operating for several weeks north-west off the island of Helgoland. Ship cruises with an undulating towed fish were carried out two to four times per year along a repeated grid covering the German Bight with the MARNET stations at its crossing points. For details on the moving platforms used in COSYNA, see Table 3.

All data are transferred in near-real time to the COSYNA data server and are publicly available in the COSYNA data portal (http://codm.hzg.de/codm/). Quality control processes are applied and data are flagged accordingly following SeaDataNet definitions ${ }^{1}$.

\subsection{Stationary measurements}

Six fixed stations are the central element of COSYNA and serve as platforms to record point-like time series of meteoro-

\footnotetext{
${ }^{1}$ http://seadatanet.maris2.nl/v_bodc_vocab/browse.asp?order= entrykey\&=L201
} 
Table 3. Fixed platforms used in COSYNA. Abbreviations: M: meteorology, P: physical oceanography, B: biogeochemistry. For abbreviations of the partner institutions, see Table 1.

\begin{tabular}{|c|c|c|c|c|c|}
\hline Platform & Years & Position & $\begin{array}{r}\text { Mean tidal } \\
\text { range }(\mathrm{m})\end{array}$ & Parameters & Partners \\
\hline Pole Hörnum Basin & $\begin{array}{l}2002-2013 \\
\text { (Mar-Nov) }\end{array}$ & $\begin{array}{l}54^{\circ} 47.6^{\prime} \mathrm{N} \\
008^{\circ} 27.1^{\prime} \mathrm{E}\end{array}$ & 2.3 & $\mathrm{M}, \mathrm{P}, \mathrm{B}$ & HZG \\
\hline Pole Elbe Estuary & $\begin{array}{l}\text { 2012-2013 } \\
\text { (Mar-Nov) }\end{array}$ & $\begin{array}{l}53^{\circ} 51.5^{\prime} \mathrm{N} \\
008^{\circ} 56.6^{\prime} \mathrm{E}\end{array}$ & 2.8 & M, P, B & HPA, HZG \\
\hline Pole Spiekeroog & $\begin{array}{l}\text { 2002-now } \\
\text { (year round) }\end{array}$ & $\begin{array}{l}53^{\circ} 45.0^{\prime} \mathrm{N} \\
007^{\circ} 40.3^{\prime} \mathrm{E}\end{array}$ & 2.8 & $\mathrm{M}, \mathrm{P}, \mathrm{B}$ & ICBM \\
\hline FerryBox FINO-3 & $\begin{array}{l}\text { 2011-2016 } \\
\text { (year round) }\end{array}$ & $\begin{array}{l}55^{\circ} 11.7^{\prime} \mathrm{N} \\
007^{\circ} 9.5^{\prime} \mathrm{E}\end{array}$ & 0.9 & $\mathrm{P}, \mathrm{B}$ & HZG \\
\hline FerryBox Cuxhaven & $\begin{array}{l}\text { 2010-now } \\
\text { (year round) }\end{array}$ & $\begin{array}{l}53^{\circ} 52.6^{\prime} \mathrm{N} \\
008^{\circ} 42.3^{\prime} \mathrm{E}\end{array}$ & 2.9 & $\mathrm{P}, \mathrm{B}$ & HZG \\
\hline Lander & & n.a. & n.a. & $\mathrm{P}, \mathrm{B}$ & MARUM, AWI, HZG \\
\hline $\begin{array}{l}\text { Underwater Node } \\
\text { Helgoland }\end{array}$ & $\begin{array}{l}\text { 2012-now } \\
\text { (year-round) }\end{array}$ & $\begin{array}{l}59^{\circ} 11^{\prime} \mathrm{N} \\
008^{\circ} 52.8^{\prime} \mathrm{E}\end{array}$ & & $\mathrm{P}, \mathrm{B}$ & AWI, HZG \\
\hline $\begin{array}{l}\text { Underwater Node } \\
\text { Spitsbergen }\end{array}$ & $\begin{array}{l}\text { 2012-now } \\
\text { (year-round) }\end{array}$ & $\begin{array}{l}78^{\circ} 92^{\prime} \mathrm{N} \\
011^{\circ} 9^{\prime} \mathrm{E}\end{array}$ & & $\mathrm{P}, \mathrm{B}$ & AWI, HZG \\
\hline Marine Radar Fino & $\begin{array}{l}\text { 2011-now } \\
\text { (year-round) }\end{array}$ & $\begin{array}{l}55^{\circ} 11.7^{\prime} \mathrm{N} \\
007^{\circ} 9.5^{\prime} \mathrm{E}\end{array}$ & & $\mathrm{M}, \mathrm{P}$ & HZG \\
\hline Marine-Radar Sylt & $\begin{array}{l}\text { 2012-now } \\
\text { (year-round) }\end{array}$ & $\begin{array}{l}54^{\circ} 49.2^{\prime} \mathrm{N} \\
8^{\circ} 16.8^{\prime} \mathrm{E}\end{array}$ & & $\mathrm{M}, \mathrm{P}$ & HZG \\
\hline HF-Radar Sylt & $\begin{array}{l}\text { 2009-now } \\
\text { (year-round) }\end{array}$ & $\begin{array}{l}54^{\circ} 49.2^{\prime} \mathrm{N} \\
8^{\circ} 16.8^{\prime} \mathrm{E}\end{array}$ & & $\mathrm{P}$ & HZG \\
\hline HF-Radar Büsum & $\begin{array}{l}\text { 2009-now } \\
\text { (year-round) }\end{array}$ & $\begin{array}{l}54^{\circ} 7.2^{\prime} \mathrm{N} \\
8^{\circ} 51.6^{\prime} \mathrm{E}\end{array}$ & & $\mathrm{P}$ & $\mathrm{HZG}$ \\
\hline $\begin{array}{l}\text { HF-Radar } \\
\text { Wangerooge }\end{array}$ & $\begin{array}{l}\text { 2009-now } \\
\text { (year-round) }\end{array}$ & $\begin{array}{l}53^{\circ} 47.4^{\prime} \mathrm{N} \\
7^{\circ} 55.2^{\prime} \mathrm{E}\end{array}$ & & $\mathrm{P}$ & HZG \\
\hline
\end{tabular}

Table 4. Moving platforms used in COSYNA. Time resolution is given between repeated measurements at the same location. Abbreviations: M: meteorology, P: physical oceanography, B: biogeochemistry; S: water surface, U: upper water column, FC: full water column. The abbreviations of the partner institutions are explained in Table 1.

\begin{tabular}{lllll}
\hline Platform & Vertical range & Time resolution & Parameters & Partner \\
\hline FerryBox & U & 1/2 day to a week & P, B & HZG \\
Glider & FC & days to months & P, B & HZG \\
Seabird & U & - & P & FTZ \\
Satellites & S & 2 times in 3 days & B & HZG \\
Ship surveys & FC & months & M, P, B & HZG \\
\hline
\end{tabular}

logical and marine parameters. They provide high-frequency observations to resolve variability well below tidal periods in order to estimate statistically significant tidal fluxes as well as long-term records or trends over several years at the same location. Measuring poles were implemented at three tidal inlets, the inner Hörnum Basin, Jade Bay, and the Otzumer Balje close to the island of Spiekeroog, to capture the hydrodynamics and suspended particulate matter concentrations (SPMCs) typical of the East Frisian and North Frisian Wadden Sea. An additional pole was placed in the outer Elbe Estuary (Fig. 1).

While the inner Hörnum Basin represents the zero usage zone of the National Park of the North Frisian Wadden Sea,
Jade Bay is exposed to intense activity of building a new deep water port. The Otzumer Balje discharges a catchment area that is typical of the East Frisian Wadden Sea and was intensely investigated during the ELAWAT ecosystem research project (Dittmann, 1999). The Elbe pole was operated to contribute to the sediment management plan of the Elbe Estuary and to complement the data of the stationary Cuxhaven FerryBox on the southern side of the Elbe mouth. The FerryBox on FINO3 captures offshore conditions in the German Bight. All these stations are described in the following in more detail (Table 3). 


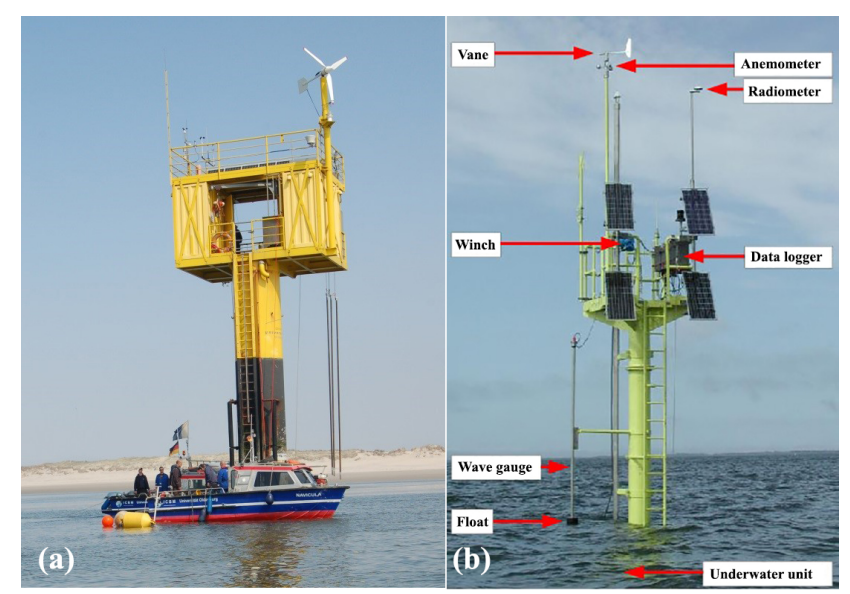

Figure 4. The measuring poles at Spiekeroog (a) and in the inner Hörnum tidal basin (b). For details, see Sect. 5.1.

\subsubsection{Poles Hörnum Basin, Jade Bay, and Elbe Estuary}

The poles at the inner Hörnum Basin, Jade Bay, and in the Elbe Estuary were mounted from March to November to prevent ice damage in the winter months. They consisted of a $15 \mathrm{~m}$ long steel tube, $5 \mathrm{~m}$ of which were jetted into the sea bed. A platform accessible via a ladder was mounted on top of the $40 \mathrm{~cm}$ diameter tube, resulting in an overall length of $18 \mathrm{~m}$ (Fig. 4). The platform carried meteorological sensors and a radiometer, solar panels for energy supply, an automated yet remotely controllable water sampler, and logger boxes for temporary data storage and wireless communication. A manual winch was used to retrieve the underwater instrument unit for maintenance. This unit was mounted with its lower end $1 \mathrm{~m}$ above the seafloor. It was equipped with sensors for all COSYNA standard observables of physical oceanography and biogeochemistry (Onken et al., 2007; Table 2).

In order to reduce sensor fouling, the underwater unit was cleaned at least twice a month. Possible sensor drift and cleansing effects were monitored by direct comparison with a well-calibrated reference system before, during, and after maintenance. Water samples were taken during maintenance to relate optical signals to SPMC.

To observe heat fluxes between the tidal flats and the water body, a vertical temperature sediment profiler was developed and deployed in the intertidal sediments close to the pole (Onken et al., 2010). It was operated for more than a year. At a distance of 5 nautical miles, an additional mooring with an upward-looking ADCP (acoustic Doppler current profiler) and a Datawell wave rider buoy was deployed.

In order to compute along-channel fluxes in the Hörnum Basin, occasional ship surveys were carried out over full tidal cycles relating across- and along-channel transects to the pole data. They were complemented by water samples and turbidity measurements. As an example, measurements over

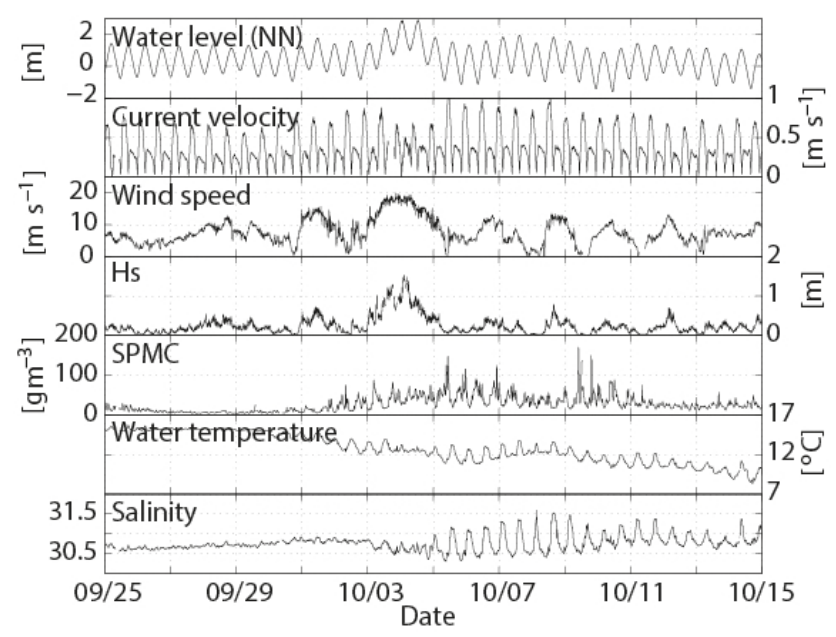

Figure 5. Time series of the measuring pole in the Hörnum Basin showing 3 weeks of data with a sampling frequency of $10 \mathrm{~min}$.

3 weeks are shown (Fig. 5) comprising a significant wind event with peak velocities up to $20 \mathrm{~ms}^{-1}$ resulting in a sea level rise of more than $1.5 \mathrm{~m}$ and significant wave heights of up to $1.7 \mathrm{~m}$. Water temperature and salinity after the storm exhibit the characteristic tidal (mainly M2) variability. Current velocities are predominantly at frequency M4, with a clear ebb-flood asymmetry. SPMC shows a complex variability reflecting the M4 tidal current dependencies as well as horizontal along-channel gradients. Interestingly, the onset of the rise in SPMC and its peak value lag behind the significant wave height by nearly one tidal period, indicating that the source of the additionally suspended material is located remotely from the pole.

The observations at the pole also indicate that the steady import of particulate matter is closely connected to the specific thermodynamic processes of the amphibic Wadden Sea area (Burchard et al., 2008; Onken et al., 2007; Onken and Riethmüller, 2010; Flöser et al., 2011).

\subsubsection{Pole Spiekeroog}

Time series of oceanographic, meteorological, and biogeochemical data have been continuously recorded since 2002 at a measuring pole of the Institute for Chemistry and Biology of the Marine Environment in the tidal channel of the Otzumer Balje close to the island of Spiekeroog (Figs. 1 and 4; Reuter et al., 2009; Badewien et al., 2009). The Spiekeroog time-series station (position $53^{\circ} 45^{\prime} 0.10^{\prime \prime} \mathrm{N}$, $007^{\circ} 40^{\prime} 16.3^{\prime \prime} \mathrm{E}$, mean sea level $13 \mathrm{~m}$ ) consists of a $35.5 \mathrm{~m}$ long pole with a diameter of $1.6 \mathrm{~m}$ that is driven $10 \mathrm{~m}$ into the sediment. The temperature, conductivity, and pressure sensors are deployed within five horizontal tubes $(1.5,3.5,5.5$, 7.5 , and $9 \mathrm{~m}$ above the seafloor) that are aligned in the main current direction. A platform is mounted on top of the pole, about $7 \mathrm{~m}$ above sea level. It consists of two laboratory con- 
tainers hosting a second platform at $12 \mathrm{~m}$ above sea level that is equipped with solar panels, a wind turbine, and meteorological sensor systems. Oceanographic sensors are installed in special tubes within the pole that are oriented in the main direction of the tidal flow. An acoustic Doppler current profiler is mounted $1 \mathrm{~m}$ above the seafloor on a horizontal arm of $12 \mathrm{~m}$ length. The Spiekeroog time-series station is capable of withstanding storm events and ice conditions. It has been part of COSYNA since 2012.

The acquired data sets are fundamental for the improvement and validation of model results (Burchard and Badewien, 2015; Grashorn et al., 2015; Lettman et al., 2009; Staneva et al., 2009; Burchard et al., 2008) as well as to answer various research questions (Rullkötter, 2009; Badewien et al., 2009; Hodapp et al., 2015; Meier et al., 2015; Holinde et al., 2015) such as concerning the impact of storm surges, algal blooms on sediment dynamics, and exchange processes. The data sets are also valuable for assessing the longterm variability of oceanographic and biological parameters and determining anthropogenic impacts. The experience gained at the pole also helped to improve fouling-prone sensing methods and quality assurance (Garaba et al., 2014b; Schulz et al., 2015; Oehmcke et al., 2015).

\subsubsection{Stationary FerryBoxes}

As part of the COSYNA network, a stationary FerryBox was installed inside the pole of research platform FINO3. Water is pumped from approximately 5 and $16 \mathrm{~m}$ below mean sea level height for the continuous analysis of near-surface and seafloor waters. The FerryBox is equipped with sensors for standard oceanographic parameters (Table 1). Temporarily, nutrient analysers and a $p \mathrm{CO}_{2}$ sensor were added.

Despite harsh operating conditions, the FerryBox has been operational since July 2011, with short interruptions during storm periods that were caused by sea spray and condensation that occurred notwithstanding the use of a heated steel cabinet for the protection of its electronics. Due to its remote position in the North Sea, personnel and spare parts had to be transported by helicopter to the platform for maintenance. Weather conditions therefore constrained the accessibility of the platform and sensors requiring regular maintenance could only be used temporarily. The software was operated remotely.

Since August 2010, a stationary FerryBox has also been installed in a container directly at the waterfront of Cuxhaven Harbour. It samples the tidally influenced, highly turbid lower Elbe River, the main freshwater discharge into the COSYNA observation area. The FerryBox was complemented by the Elbe Estuary measurement pole located $18 \mathrm{~km}$ upstream on the northern side of the river (Sect. 5.1.1) to contribute to a better understanding of the SPM dynamics and transport through the Elbe estuarine turbidity zone into the German Bight.

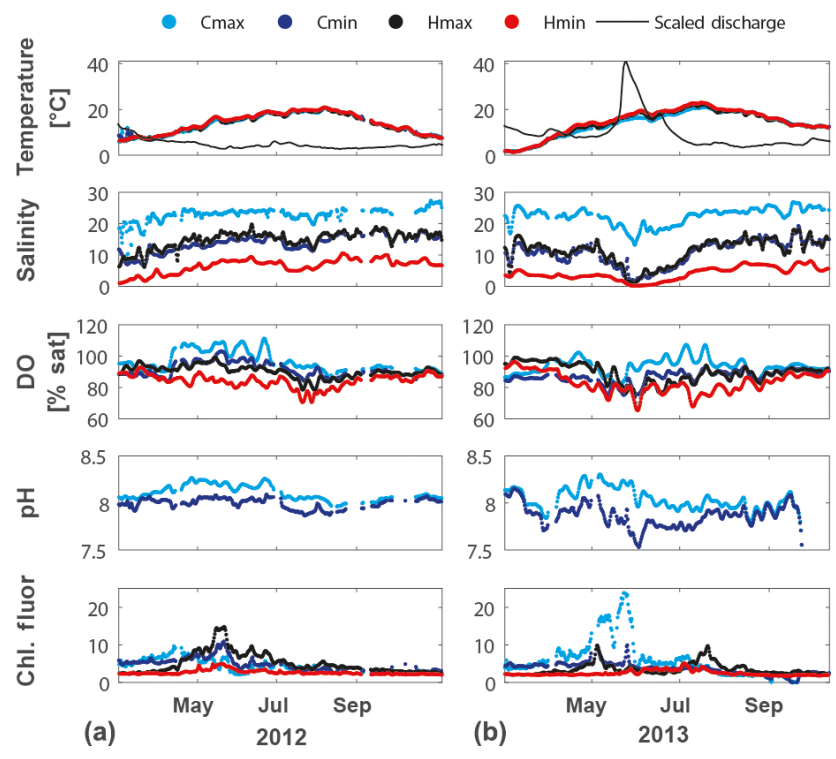

Figure 6. Time series of the stationary FerryBox located at Cuxhaven at the Elbe River mouth for 2012 (a) and 2013 (b). Top to bottom: water temperature and Elbe River discharge $\left(\mathrm{m}^{3} \mathrm{~s}^{-1}\right)$ at Neu Darchau station scaled by dividing it by 100 (thin black line), salinity, dissolved oxygen saturation (DO), $\mathrm{pH}$, and chlorophyll $a$ fluorescence. Shown are the Cuxhaven values at low tide (dark blue, Cmin), high tide (light blue, Cmax) and from the Elbe Estuary measurement pole at low tide (red, Hmin) and high tide (black, Hmax).

The water intake is located at a mean depth of $4 \mathrm{~m}$. The oceanographic sensors are described in Sect. 5.4. The FerryBox is also equipped with a nitrate, phosphate, and silicate analyser as well as a fluorescence-based instrument for phytoplankton group determination. A meteorological station mounted on the top of the container provides wind speed and global radiation values.

Due to its easy and constant accessibility, the Cuxhaven FerryBox is an ideal platform for the testing of the long-term performance of new sensors under environmental conditions.

As an example, a time series of several parameters is shown for 2012 and 2013 (Fig. 6). A strong discharge period in the summer of 2013 led to a substantial decrease in salinity, with nearly freshwater conditions at low water for a 2-week period (Voynova et al., 2017).

\subsection{Ocean gliders}

Ocean gliders are autonomous underwater vehicles, propelled by a buoyancy engine. In the last decade they have become an established oceanographic platform in the open ocean, autonomously collecting data with a high temporal resolution along (re)programmable transects. Due to their operational flexibility and a long endurance of the order of months, gliders sample the oceans at low cost in a way no other platforms currently do (Testor et al., 2010). 


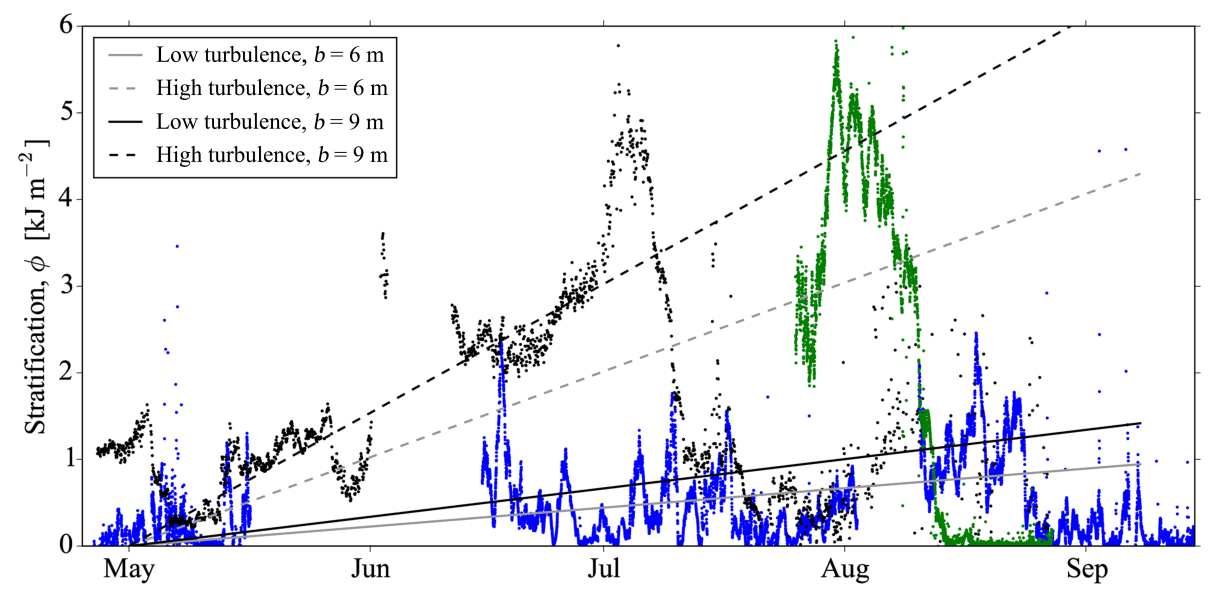

Figure 7. Measurements showing the observed buildup of stratification $\phi$ over the summer months unaffected by offshore construction (dots; Carpenter et al., 2016) and the estimated rate of stratification removal by the turbine foundation structures in offshore wind farms (straight lines). The stratification is computed as $\phi(t)=\int_{0}^{H}\left[\rho_{\operatorname{mix}}-\rho(z, t)\right] g z \mathrm{~d} z$, with water depth $H$, density $\rho$, gravitational acceleration $g$, vertical coordinate $z$, and time $t$. Measurements are from a thermistor mooring at Marnet station NSB3 in 2009 (black dots); glider data are collected in the vicinity $\left(54^{\circ} 40.8^{\prime} \mathrm{N}, 6^{\circ} 43.9^{\prime} \mathrm{E}\right.$ ) in 2014 (green dots) and from larger-scale transects passing through NSB3 in 2012 (blue points). The rate of stratification removal for thermocline thicknesses $b=6,9 \mathrm{~m}$ is based on a simple 1-D analytical model (Carpenter et al., 2016).

The use of ocean gliders in shallow coastal waters is, however, challenging. COSYNA and a few other observatories have pioneered this particular use. Due to bathymetric constraints, currents can reach magnitudes in excess of the nominal glider speed, making it difficult to follow a prescribed transect. Intense commercial and recreational shipping traffic significantly increases the likelihood of a glider-ship collision (Merckelbach, 2013). This will almost certainly result in the loss of the glider and possibly in a hull rupture, if a fast lightweight craft is involved (Drücker et al., 2015). Therefore, COSYNA collaborates closely with the authority responsible for safety regulations in the German sector of the North Sea (Wasser- und Schifffahrtsamt) to develop prediction methodologies to mitigate the risk at sea involving gliders (Merckelbach, 2016).

COSYNA maintains three Slocum Littoral Electric gliders (Jones et al., 2005). These gliders have been used in the German sector of the North Sea in different operational modes. Gliders are particularly well suited for surveying repeated transects over long periods of time (months). Their long endurance makes it viable to run two gliders in an alternating service. While one glider is operational, the second one is refurbished. The gliders have also been deployed for shorter, targeted experiments. The use of multiple gliders provides additional spatial information. In order to fly gliders in formation, operational techniques have been developed so that they act as a single entity facilitating the interpretation of the spatial variability. The measurements taken with COSYNA gliders are available on CODM. With the help of a Java applet, glider data can be visualised in three dimensions (Breitbach et al., 2016).
The evolution of stratification during 2012 and part of 2014 is shown in Fig. 7 to illustrate glider measurements. The data were collected by two gliders in alternating service in 2012, and within a single experiment in 2014. From May to August, the potential energy and stratification of the water column increase due to solar heat flux. During that time, the water column is partially mixed by wind and waves at several instances. After September, mixing dominates and the heat fluxes are too low to create a stable stratification. Data from 2014 show interannual variability with a strong stratification in August and a subsequent complete mixing of the water column caused by a storm. After this event, the stratification was not restored.

\subsection{High-frequency radar system}

In order to detect surface currents, a high-frequency (HF) radar network was established in the German Bight of the North Sea. It consists of three "Wellen Radar" (WERA) systems (Gurgel et al., 1999) located on the islands of Sylt and Wangerooge and in Büsum (Fig. 8).

The radar signal propagates along the ocean surface beyond the horizon and is backscattered by surface waves with wavelengths between 5 and $50 \mathrm{~m}$ (half the electromagnetic wavelength of the radar). The WERA systems typically cover a range distance of $100 \mathrm{~km}$ with a resolution of $1.5 \mathrm{~km}$. All systems transmit via a rectangular array of four antennas with a total power of $32 \mathrm{~W}$. The systems on Sylt and in Büsum operate at $10.8 \mathrm{MHz}$ with a linear receiver array consisting of 12 antennas, while the radar on Wangerooge operates at 12.1 MHz with a 16-antenna array. 

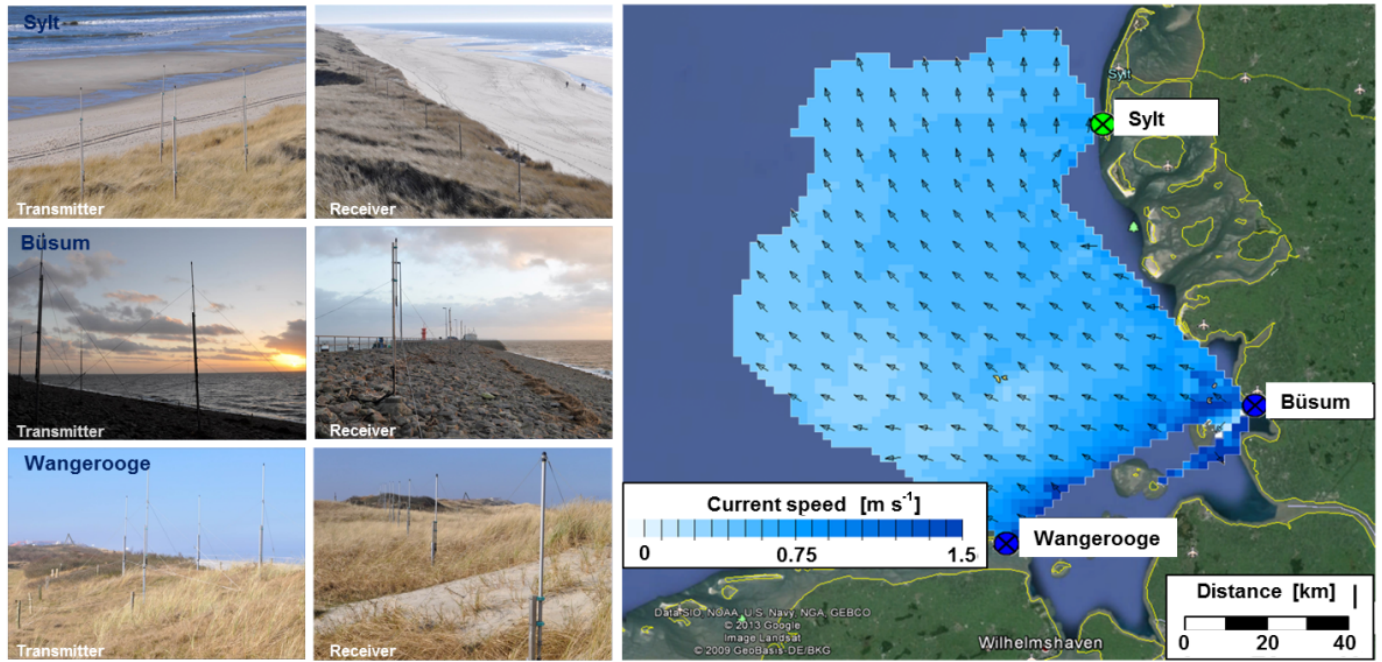

Figure 8. HF radar system in the German Bight with its three stations in Büsum and on the islands of Sylt and Wangerooge. The right panel shows an example of the 2-D current field derived from overlapping radar signals.

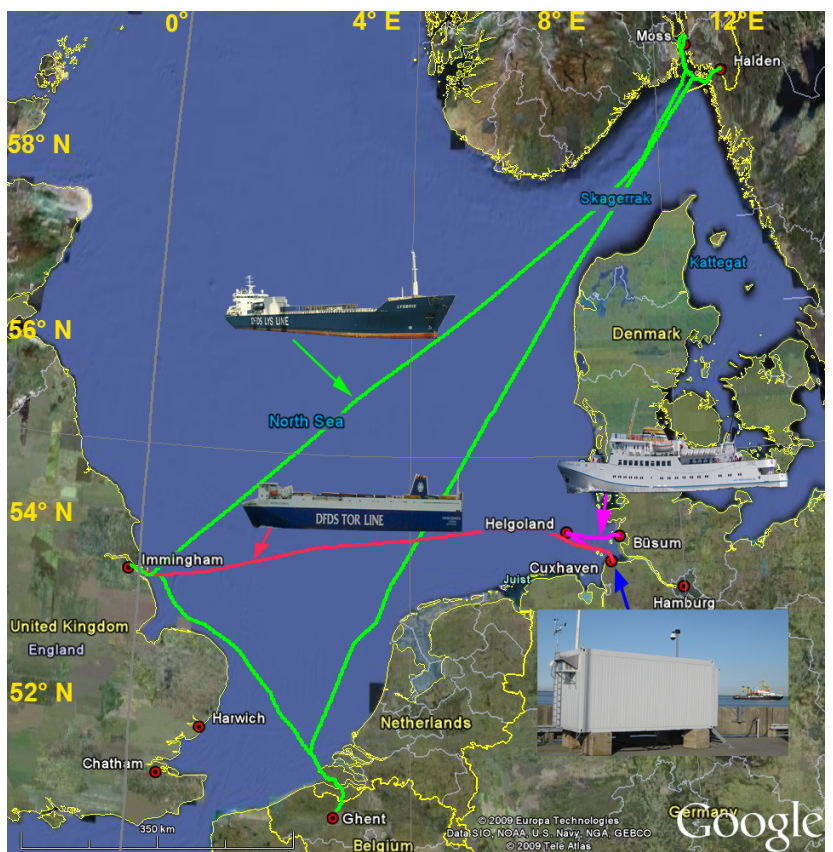

Figure 9. Map of FerryBox routes and stationary platforms equipped with FerryBoxes.

The acquired data are subject to quality control and are publicly available within $30 \mathrm{~min}$ of acquisition. In an additional processing step, the radial components of each radar site are assimilated into a numerical simulation model (Stanev et al., 2015) that is also used for short-term forecasts.

Since 2013, the HF radar network has also been used for ship detection, tracking, and fusing information of the radars with other sources of ship information such as from the Automated Identification System. Although the HF radar net- work was set up for the retrieval of oceanographic parameters, leading to a limited resolution and detection performance, ship detection can be performed at each HF radar station every $33 \mathrm{~s}$ (Dzvonkovskaya et al., 2008). Tracking and fusion are performed as a post-processing task utilising state-of-the-art algorithms (Bruno et al., 2013; Maresca et al., 2014; Vivone et al., 2015).

\subsection{FerryBox}

In order to obtain oceanographic near-surface variables in a cost-effective way on a routinely basis, FerryBox systems have been developed within COSYNA and were installed on several ships-of-opportunity such as ferries or cargo ships, research vessels, or as stationary units (Fig. 9). They deliver key physical state variables of the North Sea and the Arctic coast off Svalbard and fill gaps concerning robust biogeochemical observations of the oceans. In particular, observations of the coastal carbon cycle with high temporal and spatial resolution along the ship tracks help to understand impacts of climate change or eutrophication on productivity, as well as the influence of single events such as storms or floods on the system. The recorded variables include temperature, conductivity, salinity (derived from temperature and conductivity), chlorophyll $a$ fluorescence, turbidity, dissolved oxygen (DO), the partial pressure of $\mathrm{CO}_{2}\left(p \mathrm{CO}_{2}\right), \mathrm{pH}$, alkalinity, nutrients, and algal groups (derived from patterns of algal fluorescence by excitation at different wavelengths). The data are used for model validation (Petersen et al., 2011; Haller et al., 2015) and assimilation studies (Stanev et al., 2011; Grayek et al., 2011; Fig. 10).

The FerryBox is a modular system that can be easily extended with additional sensors. Compared to other platforms, such as buoys, the FerryBox systems have fewer limitations 

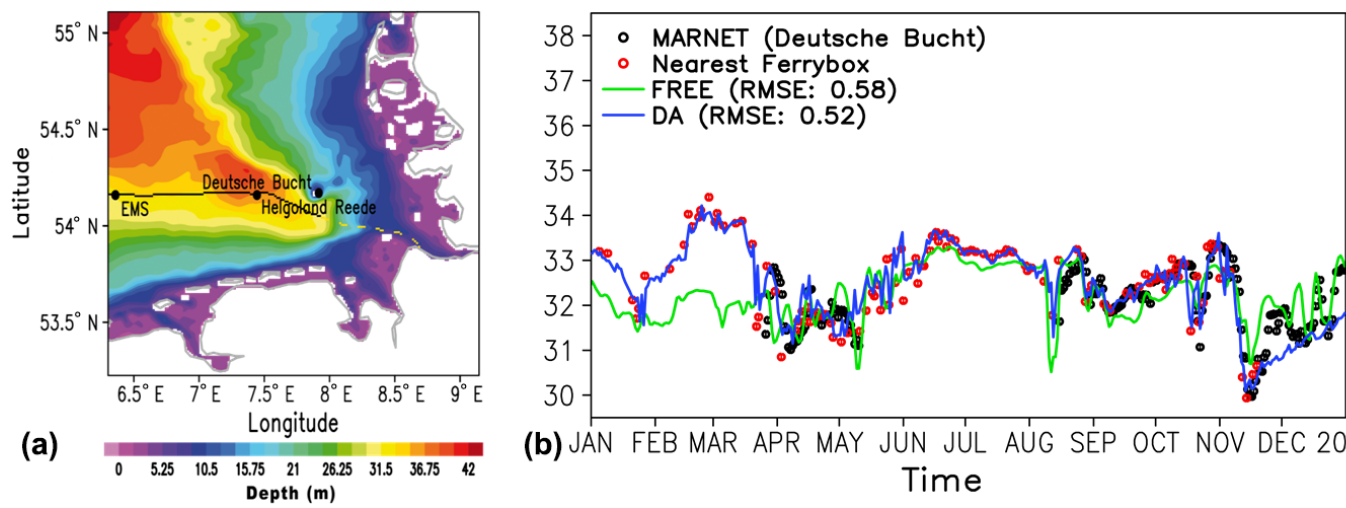

(b) JAN FEB MAR APR MÁY JU'N JU'L AÚG SEP OCT NOV DEC 2007

Figure 10. (a) Topography of the German Bight and FerryBox track. (b) Comparison of simulated sea surface temperature from a free model run and a run with data assimilation (DA) against MARNET and the nearest FerryBox observations (Grayek et al., 2011).

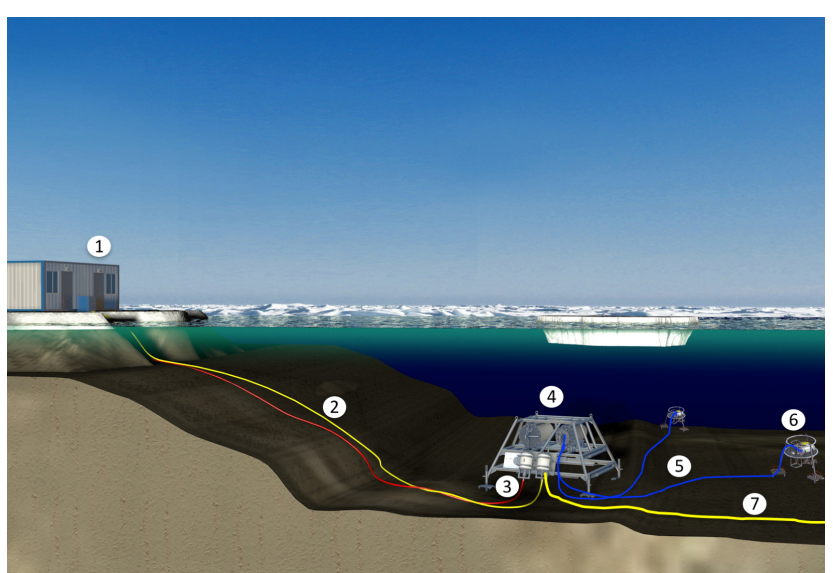

Figure 11. Set-up of the COSYNA Underwater-Node System with (1) land-based server and power supply, (2) cable connection (max. $10 \mathrm{~km}$ ) to the first primary underwater node, (3) breakout box to connect the primary node to the underwater cable, (4) primary node system, $(5,6)$ cable connection (max. $70 \mathrm{~m}$ ) to sensor units, and (7) cable connection to a second node. A third node can be connected to the second node.

due to space, power consumption, or harsh environmental conditions, allowing the operation of experimental and less robust sensors (Petersen, 2014). Due to a self-cleaning mechanism, the system maintenance intervals can be extended up to several months. All data are stored in the FerryBox system and are transferred to the COSYNA server when the vessel has a stable Internet connection.

\subsection{Underwater-Node System}

While cabled underwater observatory technology has been developed for deep sea research applications over the last decades, cabled underwater observatories for shallow water were only recently initiated due to the predicted dramatic effects of climate change especially in the world's coastal re-
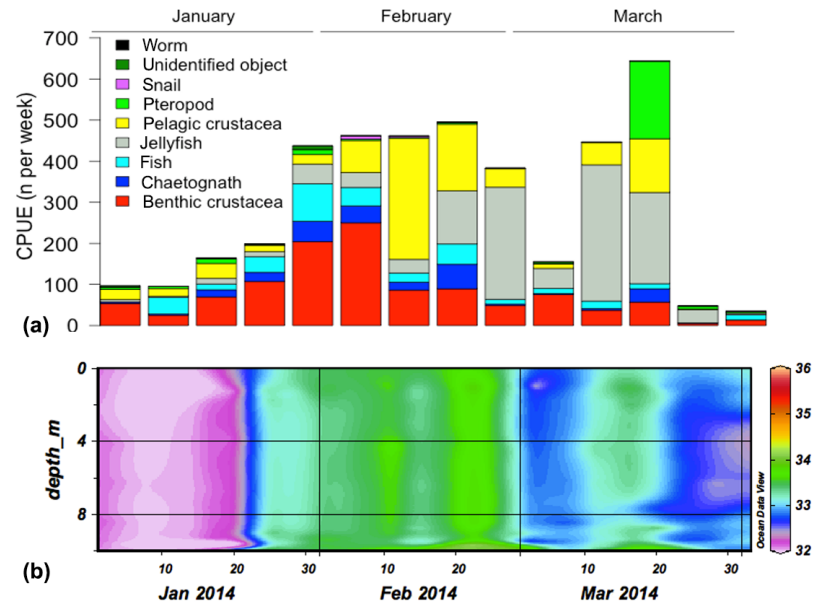

Figure 12. (a) The temporal abundances of the main biota groups assessed with a stereo-optic sensor attached to the UnderwaterNode System in Spitsbergen from January 2014 to March 2014. CPUE (catch per unit effort) refers to the total number of organisms per group counted per week. (b) The temporal and spatial patterns of salinity in the depth range between 0 and $10 \mathrm{~m}$ assessed with one remote controlled vertical CTD profile per day during the same time period when the biota measurements (upper panel) were done.

gions. They are needed as core research infrastructures when either a continuous high-frequency or real-time monitoring of hydrographical or biological data is required or when scientific instrumentation requires more power than batteries can provide. Cabled underwater observatories enable new research approaches in marine science by providing longterm time series. Similar to atmospheric or terrestrial research, they are suitable to form the backbone of international coastal and climate change research.

The harsh environments of shallow waters with extreme wave impact, storms, sea ice, strong currents, as well as biofouling and the direct impact of fishing vessels require the development of very robust cabled systems. COSYNA started 
with this development in 2010, with the goal of observing multidisciplinary processes in the harsh environmental conditions in the North Sea and in the Arctic areas - in particular during storms and in winter when access with vessels is difficult or impossible.

The COSYNA Underwater-Node System is designed for water depth between $10 \mathrm{~m}$ (in high-energy environments like the North Sea) to a maximum of $300 \mathrm{~m}$. It comprises a land based power unit and server providing 1000 VDC, a GBitnetwork connection, and virtual computer technology for up to 20 different users. This land-based control system is connected to the underwater node unit via a fibre-optic and power hybrid cable that can be up to $10 \mathrm{~km}$ long (Fig. 11).

The underwater unit is built as a basic lander system. Up to 10 underwater plugs provide power and network connection. The underwater unit can be outfitted with an uninterrupted low-power battery supply for 6-8 $\mathrm{h}$ operating time to enable temporary disconnection from the high-voltage electricity. From this central underwater node unit (Fig. 114), sensors or sensor units with a power consumption of up to $200 \mathrm{~W}$ (Fig. 11 5-6) can be connected via a cable up to $70 \mathrm{~m}$ long. Communication and data transfer with the attached sensors or sensor units are realised via TCP/IP. Completely separated ports allow scientists to directly communicate with the instruments independently of other users. From the primary node system, an uplink power and network connection allows the serial connection of a secondary and tertiary underwater node unit (Fig. 11 7) to reach a maximal range of $30 \mathrm{~km}$ from the land-based support unit.

Since 2012, COSYNA has operated two Underwater-Node Systems. One node system with 10 separated ports is located off the island of Helgoland at $59^{\circ} 11^{\prime}, \mathrm{N} / 8^{\circ} 52.79 \mathrm{E}$ at $10 \mathrm{~m}$ water depth close to the "Helgoland Roads" long-term timeseries station and the MarGate AWI underwater experimental area (Wehkamp and Fischer, 2012, 2013a, b). It is operated as a permanent monitoring facility for the main hydrographical parameters in the southern North Sea (temperature, conductivity, $\mathrm{O}_{2}, \mathrm{pH}$, turbidity, currents), as a docking and support system for complex sensor systems with high power and data transfer demands, such as stereo-optical cameras (Wehkamp and Fischer, 2014), and as a test facility for the development and operation of the Underwater-Node Systems in the shallow environment of the North Sea. Since 2012, the Helgoland node system has endured two severe storms with wind speeds of up to $12 \mathrm{Bft}\left(190 \mathrm{~km} \mathrm{~h}^{-1}\right)$, providing evidence that the operation of cabled observatories is possible under extreme conditions.

The southern North Sea is well known as a high-energy environment with wind speeds above $10 \mathrm{~m} \mathrm{~s}^{-1}$ (>6 Bft) during considerable phases of the year. Research cruises with intense sampling programmes are therefore often problematic and cabled observatories provide an invaluable extension for continuous and long-term monitoring programmes. They may therefore help fill a significant gap in our understand- ing of ecosystem behaviour in coastal environments beyond 6-8 Bft.

The second continuously operated COSYNA underwater observatory has been deployed since 2012 off Svalbard at $78^{\circ} 92^{\prime} \mathrm{N}, 11^{\circ} 9^{\prime} \mathrm{E}$. It is located at the western coast of Spitsbergen close to the international research village of NyÅlesund. It comprises a FerryBox system and a COSYNA Underwater-Node System at the "Old Pier" (Fig. 3) close to the research village of NyÅlesund. It provides a continuous year-round monitoring system as well as an access point for international project partners. Since 2015, the COSYNA underwater observatory has been part of EU project JericoNext, the long-term research strategy of the NyÅlesund research council, and the Kongsfjord Flagship Program.

Also, the Svalbard observatory is operated as a permanent monitoring facility for the main hydrographical parameters in the fjord system (temperature, conductivity, $\mathrm{O}_{2}, \mathrm{pH}$, turbidity, currents) and as a docking and support system for complex sensor systems. It is fully remotely controlled and all sensors and sensor units can be accessed via the Internet from Germany. The Svalbard observatory is equipped with four access points and is specifically designed for national and international cooperation in the Kongsfjorden ecosystem. A main feature of the Svalbard observatory is a vertical profiling sensor unit, which allows one to remotely position attached sensors at a specific depth on a daily or even hourly basis. Thus, the entire water column can be sampled yearround, even under sea ice.

With the remotely controlled sensor set-up of the COSYNA Underwater-Node System, it was possible for the first time to gain data with a temporal resolution of up to $1 \mathrm{~Hz}$ with both CTD and ADCP sensors, and with highly complex sensors like a stereo-optical camera system that is able to measure abundance, species composition, and length frequency distributions of macroscopic organisms (Wehkamp and Fischer, 2014). No data set of this kind has previously been available from any Arctic ecosystem worldwide, thus providing unique insights into the dynamics of a polar ecosystem with a very high temporal and spatial resolution (Fig. 12).

\subsection{Landers}

Under the COSYNA framework, different autonomous seafloor observatories (landers) have been developed and are applied in various past and ongoing research programmes. These landers bridge the observational gap between longterm monitoring stations, remote sensing applications, and ship-based field campaigns. They are mobile, and can be used to spatially interpolate between monitoring stations and provide data with very high temporal resolution (Kwoll et al., 2013, 2014; Oehler et al., 2015a; Ahmerkamp et al., 2017). Lander operations aim at measuring various processes close to the seafloor or in the sediment and are designed to have minimal impact on the environment and quantities 
that are measured. The landers can be either operated autonomously for days or weeks at a time, or may be connected to the COSYNA Underwater-Node System that provides power and data connection for the landers.

The landers developed and used in COSYNA are (i) the SedObs (Sediment Dynamics Observatory) lander measuring seafloor dynamics, (ii) the NuSObs (Nutrient and Suspension Observatory) lander, and (iii) the FLUXSO (Fluxes on Sand Observatory) lander.

\subsubsection{Lander SedObs}

The Sediment Dynamics Observatory (SedObs) lander is used to investigate seafloor dynamics and to improve the fundamental knowledge of multi-phase flows and the interaction of physical and biological processes. The seafloor and lower water column are characterised by morphodynamic processes acting on a large range of spatial and temporal scales. Observations with SedObs focus on short-term dynamics from turbulence to tides or storm events. Particular focus is given to the interaction of water motion by currents and waves as well as the transport of sediments and other substances with the sea bed evolution under the influence of (micro-)biological stabilising and destabilising organisms (Ahmerkamp et al., 2015).

SedObs consists of a $2 \times 2 \mathrm{~m}$ steel frame with a platform providing space for battery power supply and the installation of sensors (Fig. 13). The platform rests on four adjustable and inclined legs. Foot plates provide a stable stand, prohibit subsidence, and reduce scouring around the legs. Sensors can be attached to the legs for measurements close to the sea bed. The lander is deployed with a launching frame from a research vessel orienting it in the direction of the main currents. After release of the lander, the frame is recovered in order to minimise flow disturbances. For recovery, a floating buoy with a recovery line is released acoustically. Typical deployment times exceed $25 \mathrm{~h}$ to account for the diurnal inequality in tidal variations. Deployments can be extended to longer periods of several weeks depending on measuring frequency, battery, and storage limitations, and the increasing risk of damage by trawlers.

Flow velocities and turbulence above and below the lander are measured with two acoustic Doppler current profilers. The upward-looking ADCP also captures the directional surface wave spectrum. Two acoustic Doppler velocimeters record velocity at two levels with high frequency. Turbulence characteristics are computed from highly frequent velocity fluctuations (Amirshahi et al., 2016).

The small-scale bathymetry below the lander is measured with a 3-D acoustic ripple profiler (Bell and Thorne, 1997). The sensor is installed about $1.8 \mathrm{~m}$ above the seafloor covering a circular area of $6.2 \mathrm{~m}$ diameter. Sediment transport characteristics are measured with Sequoia Lisst 100X instruments providing in situ particle size distributions of suspended sediments. Characteristics of suspended matter con- centration are provided by optical backscatter sensors and the backscattered signal strengths of the hydroacoustic instruments. Additional parameters comprise the COSYNA standard observables. Observations are complemented by investigations of benthic species as well as sedimentological and granulometric analysis (laser diffraction) of the sediments sampled with grab samplers, box corers, and multi-corer equipment.

SedObs supports several applied and fundamental research projects, such as KÜNO NOAH (North Sea Observation and Assessment of Habitats). Until 2015, 11 ship surveys were carried out, and field data were collected and analysed at different reference sites in the German Bight with sedimentological and morphological characteristics that are representative of large areas of the German EEZ in the North Sea. A combination with other COSYNA seafloor observatories has produced consistent and extensive data sets on various physical and (micro-)biological properties of the domains (Krämer and Winter, 2016). Data are published at http://www.noah-project.de.

During some parts of the tidal cycle a periodic stratification of the water column has been observed in shallow areas of the German Bight forming distinct layers that move independently with a decoupled tidal ellipticity (Krämer and Winter, 2016; Kwoll et al., 2013, 2014; Ahmerkap et al., 2017). The difference in sea bed dynamics between fair weather conditions and storms is also investigated in the research area "Seafloor Dynamics" of the Deutsche Forschungsgemeinschaft (DFG, German Research Foundation) Research Center/Cluster of Excellence "The Ocean in the Earth System".

\subsubsection{Lander NuSObs}

The NuSObs (Nutrient and Suspension Observatory) benthic lander system was designed to quantify the exchange of nutrients and oxygen across the sediment-water interface and to sample surface sediments in situ (Oehler et al, 2015a, 2015b). The aim was to study the remineralisation of organic matter, the reflux of nutrients into the bottom water, the dissolution of biogenic silica (e.g. diatoms), and transport processes across the sediment-water transition zone, such as biologically mediated transport (e.g. bioirrigation) or wave-induced pore water advection. The target area was the North Sea. Three time-series sites were selected and revisited three to four times a year in order to identify seasonal variations.

NuSObs (Fig. 13) was equipped with two "Mississippi" type chambers (Witte and Pfannkuche, 2000). After the deployment of the lander, both chambers were moved slowly into the sediment by a motor, each enclosing a sediment area of $400 \mathrm{~cm}^{2}$ for typically $12-24 \mathrm{~h}$. Each chamber was equipped with a syringe sampler (seven $50 \mathrm{~mL}$ glass syringes) to obtain water samples from the incubation chamber for subsequent chemical analysis. In addition, an oxygen optode and $\mathrm{pH}$ sensor were mounted in each chamber. The 

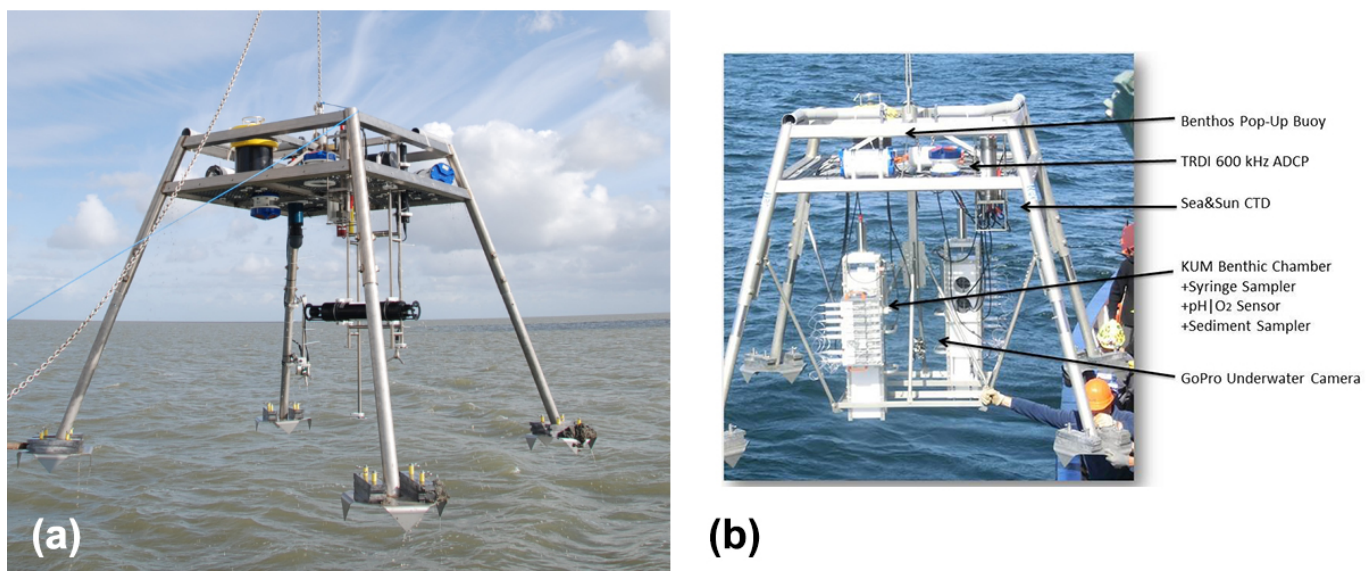

(b)

Figure 13. Deployment of landers SedObs (a) and NuSObs (b).

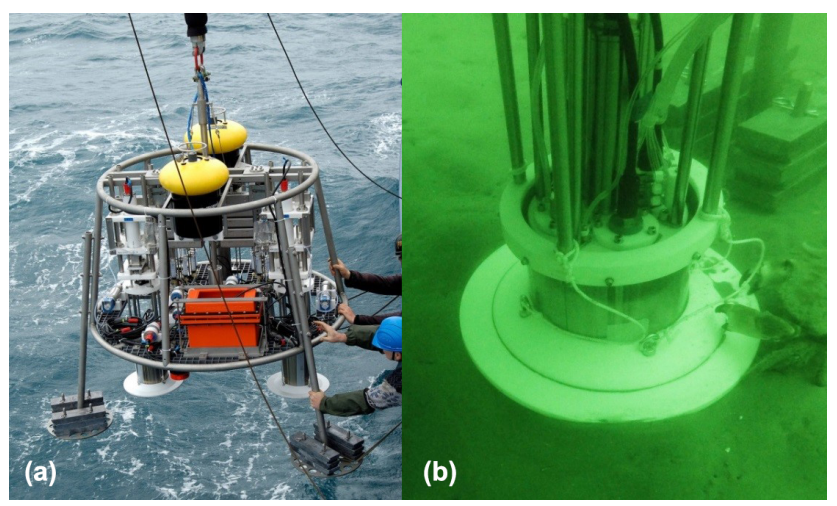

Figure 14. (a) Lander FLUXSO deployed for autonomous sampling in June 2015; (b) sampling chambers in mobile fine sand at $25 \mathrm{~m}$ depth.

syringe sampler was pre-programmed to obtain water samples from the chamber every $2-3 \mathrm{~h}$, yielding time-series data of oxygen, nitrate, or silicic acid concentrations within the chambers.

\subsubsection{Lander FLUXSO}

The FLUXSO (Fluxes on Sands Observatory) benthic lander system was recently developed for studying in situ solute fluxes of nutrients, DIC, and oxygen in permeable consolidated sediments. The goal is to assess the importance of the seafloor as a sink or source of nutrients and benthic-pelagic coupling and to study advection-related processes in permeable shelf sediments. The lander was successfully applied on sandy sediments of the North Sea (Fig. 14; Friedrich et al., 2016; Neumann et al., 2016; Ahmerkamp et al., 2017).

The lander consists of a tripod base frame that is recovered from the seafloor using two pop-up buoys (Fig. 14). Power supply is provided by a deep-sea battery. The lander contains two wiggling chambers that are both equipped with

oxygen and $\mathrm{CO}_{2}$ optodes, a $\mathrm{pH}$ sensor, and a conductivity sensor. A stirrer disk with variable speed and direction allows the simulation of advective or diffusive flow regimes in each chamber by creating rotationally symmetric pressure gradients between the center and the circumference of the enclosed sediment surface. The shape and magnitude of the pressure gradients closely resemble natural conditions. Two syringe samplers are used for tracer injection and sampling from the chambers. Outside water parameters are measured with a CTD with fluorescence and turbidity sensors, a PAR sensor, an oxygen optode and pH sensor, as well as a Doppler current sensor.

The FLUXSO lander can be deployed at the seafloor, where it autonomously measures solute fluxes between sediment and seawater using isolated sampling chambers. An innovative wiggling mechanism is used, permitting gentle and deep penetration of the chambers into consolidated sediments with minimum disturbance (Janssen et al., 2005).

\subsection{Satellite oceanography}

Satellite remote sensing is unique in providing a synoptic view over larger areas of the sea surface (Robinson, 2004). Standard algorithms are used widely to determine the optically dominant water constituents and the chlorophyll $a$ concentration in clear oceanic waters (Carder et al., 1991; Lee et al., 1998; Gohin et al., 2002). These simple band-ratio algorithms, however, often fail in optically complex coastal waters. To gain concentrations of one coastal water constituent, other optically active substance categories have to be considered in the development of algorithms for the inversion of satellite spectral data. The correction of the atmospheric influence is more sensitive and complex as it accounts for 90 to $98 \%$ of the radiance seen at the satellite. The algorithms for coastal waters developed by HZG and used in COSYNA are included in the ESA (European Space Agency) operational processing scheme for the sensors MERIS (MEdium Resolution Imaging Spectrometer) on ENVISAT (Doerffer 


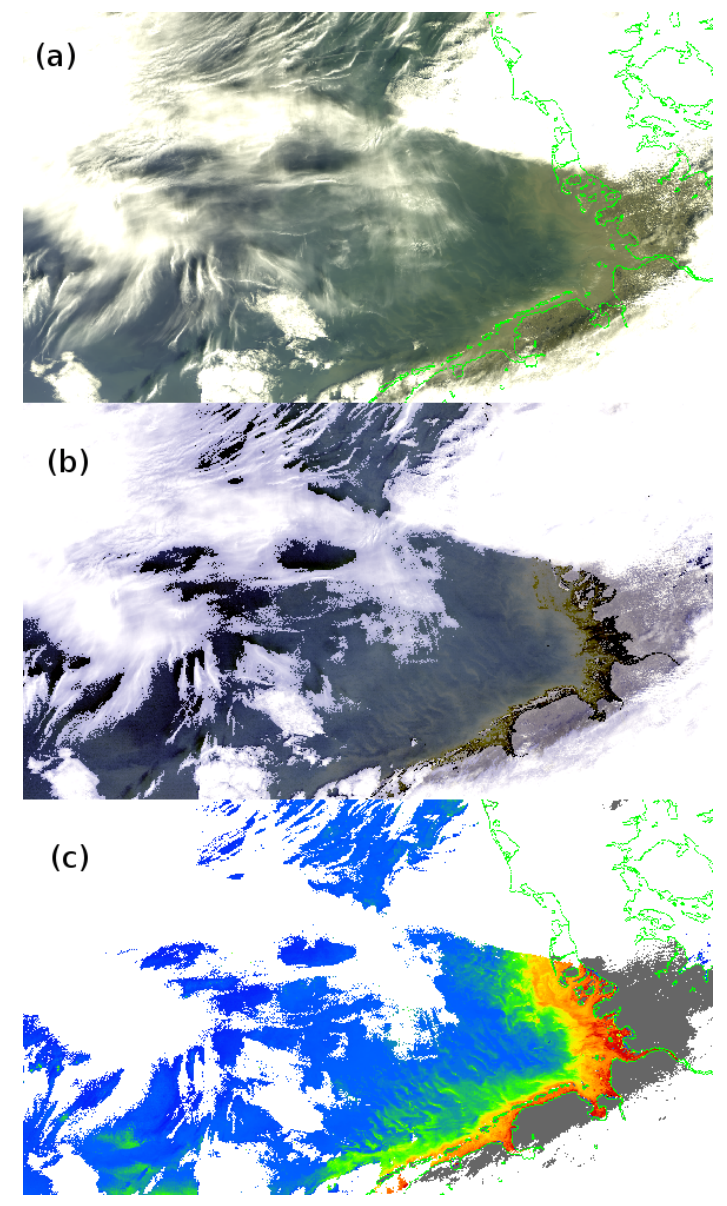

Figure 15. Satellite scene of the German Bight taken on 3 October 2012 by MERIS. (a) Radiance in the atmosphere; (b) reflectance at the bottom of the atmosphere (after atmospheric correction); (c) chlorophyll a concentration showing filaments of phaeocystis blooms along the West and East Frisian coasts.

and Schiller, 2007) and OLCI (Ocean and Land Colour Instrument) on Sentinel-3 providing chlorophyll $a$ and total suspended matter (TSM) concentrations and the absorption by chromophoric dissolved organic matter (CDOM, "Gelbstoff").

MERIS provided COSYNA data (Fig. 15) for the North Sea until 2012, when ENVISAT failed, with the adaptation of the coastal algorithm to MODIS (on AQUA) and OLCI (Ocean and Land Colour Instrument) on Sentinel-3 providing chlorophyll $a$ and total suspended matter (TSM) concentrations and the absorption of "yellow substances" (Gelbstoff) whose main part is chromophoric dissolved organic matter (CDOM).

\subsection{Seabird tracking}

Seabirds are top predators depending on marine resources. Their foraging behaviour may therefore indicate changes in their food resources which are often associated with vari-

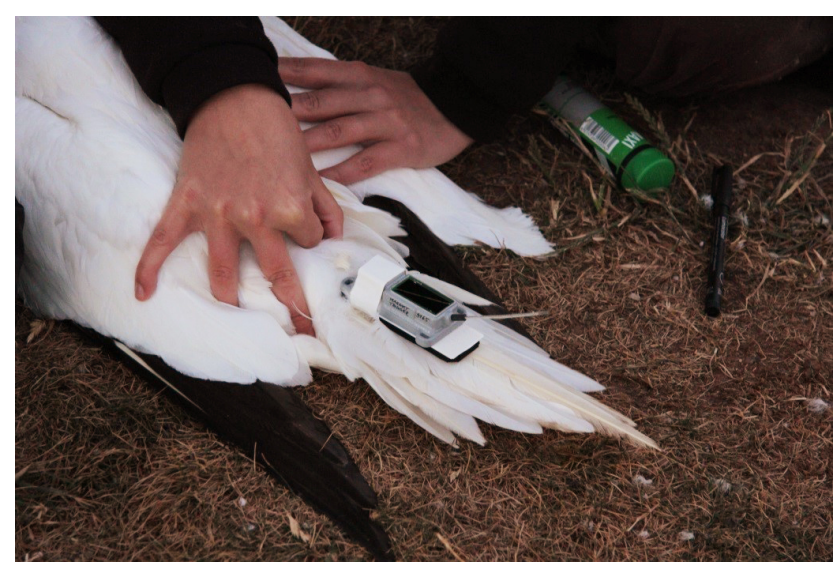

Figure 16. Solar-powered GPS data logger attached to a tail of a Northern Gannet (photo: J. Dierschke).

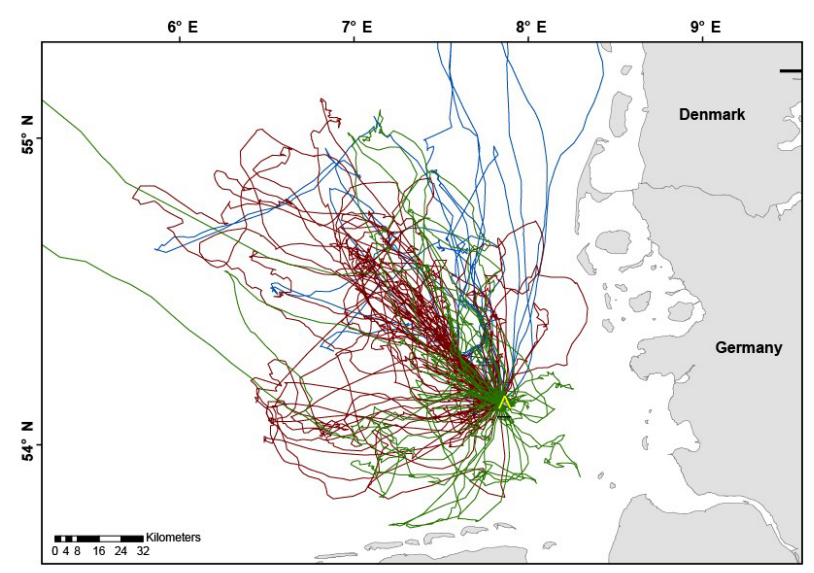

Figure 17. Foraging flights of three Northern Gannets (Morus bassanus) in 2015 starting from Helgoland.

ability in the marine environment (Furness and Camphuysen, 1997). In COSYNA, the Northern Gannet (Morus bassanus) has been selected as the target seabird species due to its size and large foraging range (Fig. 16; Garthe et al., 2017). Northern Gannets are widely distributed in the North Atlantic and breed in large colonies. Individual Northern Gannets were equipped with modern, lightweight GPS data loggers to track their flight patterns and foraging behaviour. In particular, information is collected on position, flight speed, altitude, and partly also on dive depth and water temperature. A strong feature of most modern data loggers is that they are powered by solar cells, thus enabling long-term tracking for several weeks, months, or even years. Furthermore, an increasing number of devices provide data transfer via UHF, satellite, and mobile phone networks (Wilson and Vandenabeele, 2012; Kays et al., 2015). A combination of the data collected by seabirds with environmental parameters from other COSYNA observations, such as salinity, sea surface temperature, or chlorophyll, facilitates the understanding of 
the seabirds' foraging behaviour, their likely food intake, and habitat choice (Fig. 17). On the other hand, the recorded spatial and temporal flight patterns and environmental parameters can help to characterise the environmental status of the North Sea.

\subsection{In situ mapping of the COSYNA observation area}

The regular operational observations in COSYNA primarily detect variables at the sea surface (currents observed with HF radar; chlorophyll $a$ concentration, TSM, and SPMC observed with satellite remote sensing), at constant depths at fixed high-resolution time-series stations (Poles, FINO3 platform, MARNET stations), or at constant depth along regular ship routes (FerryBox transects). In order to observe the vertical distribution of key variables and their temporal development, these observations were complemented by extended in situ mapping of the North Sea during several research cruises and glider surveys. In situ observations taken with Wadden Sea poles, FINO3 platform, MARNET stations and FerryBox are also used in modelling (Stanev et al., 2016).

In particular, the surveys aimed at investigating the representativeness of single-point time-series observations, delivering larger-scale validation data for the COSYNA remote sensing systems and numerical models, testing the functioning of new sensors for permanent missions under North Sea conditions, and relating concentrations and characteristics of living and non-living water constituents to optical surrogate variables.

The regular COSYNA mapping grid covers estuarine, Wadden Sea, and open shelf seawater (Fig. 18). It consists of four east-west and four south-north cross-shore transects and touches the fixed COSYNA and MARNET stations covering the whole German EEZ. The land side is limited by a water depth of $10 \mathrm{~m}$ and its most seaward reach by the borders of the German EEZ.

From 2009 to 2013, up to four cruises per year were carried out with RV Heincke. The cruises took place between March and October to take seasonal variations into consideration. At a ship's speed of 6 to 8 knots, the grid was completed in less than a week. During this time, the water masses did not move substantially, as confirmed by model studies using Lagrangian tracers. The observations thus provide a good approximation of the spatial distribution of the observed variables.

Along the grid lines, an undulating towed Scanfish Mark II $^{\mathrm{TM}}$ by EIVA was operated, yielding vertical profiles of oceanographic and bulk biogeochemical parameters at a vertical resolution of several centimetres and a horizontal resolution of $150 \mathrm{~m}$ at mid-water depth. A FerryBox system was used to analyse water continuously taken at a depth of $4 \mathrm{~m}$ with respect to the standard oceanographic parameters temperature, salinity, $\mathrm{pH}$, chlorophyll fluorescence, turbidity, CDOM, nutrients, dissolved oxygen, and $p \mathrm{CO}_{2}$. During the cruises, the FerryBox also served as a platform for test- ing newly developed sensors. This includes a flow-through PSICAM (Point-Source Integrating Cavity Absorption Meter) for high-frequency hyperspectral absorption coefficient measurements (Wollschläger et al., 2013, 2014), a sequential injection analysis (SIA) approach for phosphate measurement (Frank and Schroeder, 2007), as well as high-precision spectrophotometric methods for the determination of $\mathrm{pH}$ and total alkalinity (Aßmann et al., 2011; Aßmann, 2012). Vertical current profiles were recorded with an ADCP. During two cruises, gliders were operated in parallel, enhancing the spatial observation density. At the cruise track crossing points, additional vertical profiles were taken and complemented with Secchi depth determination, light transmission, and scattering spectra taken from water samples.

As an example, the spatial distributions of $\sigma_{T}$ (potential density $-1000 \mathrm{~kg} \mathrm{~m}^{-3}$ ) and chlorophyll $a$ fluorescence are shown for the cruise at the end of July 2010 (Fig. 18). Vertical density gradients at the $5 \mathrm{~m}$ thick pycnocline of up to $0.3 \mathrm{~kg} \mathrm{~m}^{-4}$ indicate a strong stratification typical of the summer months. In the outer reaches of the observation area, two pycnoclines can be discerned. In the presence of stratification, chlorophyll $a$ shows a typical deep water maximum at the upper pycnocline. The sudden increase in oxygen saturation directly above this maximum can be attributed to photosynthesising phytoplankton. By coupling the observed vertical distribution of potential density and SPMC with a modelled turbulence parameter field, the spatial distribution of settling velocities in the COSYNA observation area was derived (März et al., 2016). Characteristic scales for the coupling of physical submesoscale and mesoscale processes and the distribution of chlorophyll $a$ were identified by North et al. (2016) by applying wavelet analyses to Scanfish data.

\section{Sensor and instrument development}

In COSYNA, well-proven commercially available sensors and sensor systems are used. However, to automatically measure the main parameters that control and influence the North Sea and Arctic ecosystem, several novel, automated, and reliable sensors had to be developed and tested by the COSYNA partners. These are, in particular, sensors and samplers for biogeochemical and optical parameters as well as micropollutants. An overview is given in the following. For most of these sensors, the FerryBox was used as a test platform because it is protected from the environment, it provides a continuous seawater supply, and it offers high-frequency data acquisition and real-time data transmission.

\section{1 pH sensor}

pH can be used to estimate a system's state in terms of phytoplankton and primary production in regions of high biological activity, one of four parameters characterising the oceanic inorganic carbon system, and an indicator of the increasing 


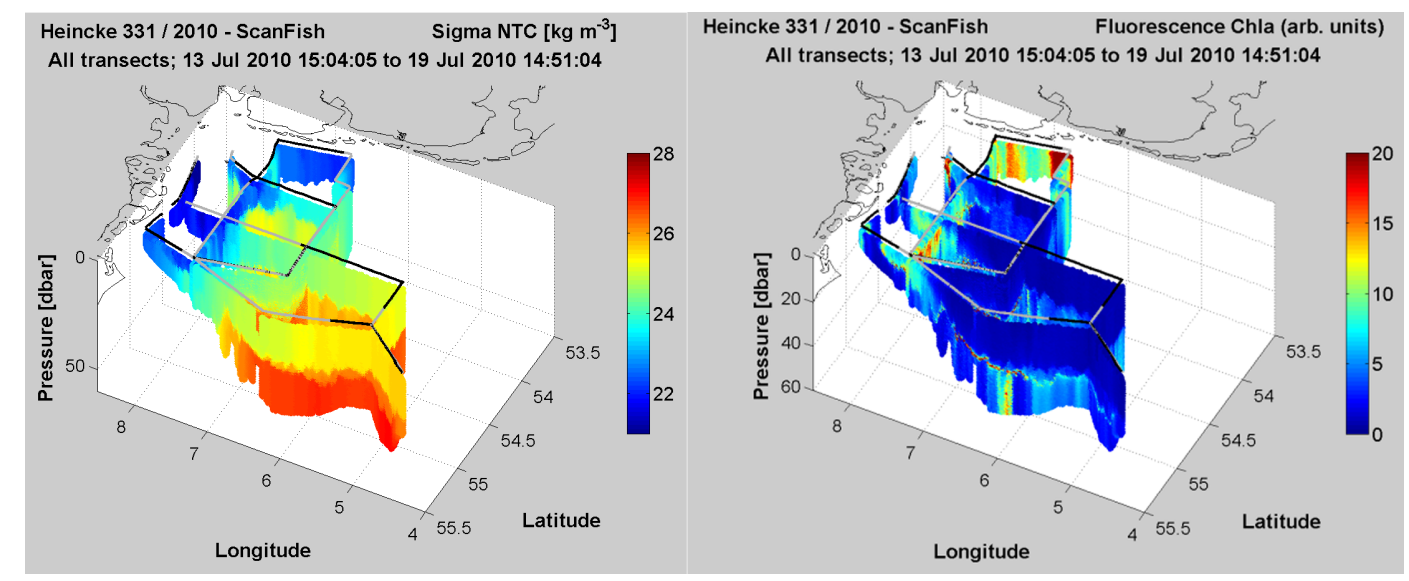

Figure 18. Spatial distribution of $\sigma_{T}$ and chlorophyll $a$ observed during RV Heincke cruise HE331 in July 2010.

acidification of seawater. In order to quantify the components of the carbon cycle in the context of climate change, a precise characterisation of the carbonate system is required.

In COSYNA, commercially available $\mathrm{pH}$ glass electrodes are routinely used. They are very sensitive to bio-fouling as bacterial biofilms on the electrodes changes the $\mathrm{pH}$ thus requiring cleaning and re-calibrating intervals of 7-10 days in summer. Although an accuracy of $\pm 0.05-0.1 \mathrm{pH}$ units can be achieved in FerryBox systems for several weeks due to their regular automatic cleaning procedures, a higher precision of $<0.01 \mathrm{pH}$ units is necessary to detect the acidification process in coastal waters with a $\mathrm{pH}$ decrease of about $0.0019 \mathrm{pH}$ units per year (Dore et al., 2009; Feely et al., 2009).

In COSYNA, a more precise sensor based on a spectrometric approach was developed (Aßmann, 2012) that detects the colour of a suitable indicator dye in a miniaturised flowthrough system. A precision of $\pm 0.0007 \mathrm{pH}$ units with an offset of $+0.0081 \mathrm{pH}$ units to a certified standard buffer was achieved for several weeks. It is, however, not yet suitable for low-energy applications.

\subsection{Alkalinity sensor}

$\mathrm{CO}_{2}$ flux estimates for the coastal ocean are subject to large uncertainties (Borges, 2005; Chen and Borges, 2009) due to strong seasonal variability. For a description of the carbonate system at least two of the following parameters have to be measured: $\mathrm{pH}$, partial pressure of $\mathrm{CO}_{2}\left(p \mathrm{CO}_{2}\right)$, total alkalinity (AT), and total dissolved inorganic carbon (CT). Because a combination of $\mathrm{pH}$ and $p \mathrm{CO}_{2}$ only yields a precision of about $1 \%$, a sensor for the additional measurement of alkalinity was developed that will allow to document the fast changing carbonate chemistry in the North Sea (Aßmann, 2012).

The approach for the photometric $\mathrm{pH}$ determination (Sect. 6.1) was modified for alkalinity, with the advantage that the same equipment can be used for both parameters. The chemical titration can be accomplished by using an "open-cell technique" applying a simple seawater model as a calculation tool. The titration occurs at $\mathrm{pH}<4.5$, leading to a removal of all carbonate species by outgassing of $\mathrm{CO}_{2}$. The precision is $\pm 1.1 \mathrm{~mol} \mathrm{~kg}^{-1}$ with an accuracy of $\pm 8 \mathrm{~mol} \mathrm{~kg}^{-1}$. In a more complex "closed-cell technique" a broader $\mathrm{pH}$ range is used and no $\mathrm{CO}_{2}$ escapes, yielding an accuracy of $\pm 0.8 \mathrm{~mol} \mathrm{~kg}^{-1}$ with a precision of $\pm 4.4 \mathrm{~mol} \mathrm{~kg}^{-1}$.

\subsection{Nutrient sensor}

COSYNA uses commercially available nutrients analysers on FerryBoxes for long-term investigations of the nutrients ammonia, nitrite, nitrate, phosphate, and silicate, which are important parameters regarding eutrophication. However, as small-scale processes often require faster sensor response times, a flow-through system was developed for the fast determination of ammonia and phosphate based on sequential injection analysis (SIA), causing a chemical reaction of both species with a reagent that can be detected by fluorescence (Frank et al., 2006). The detection limits are $0.3 \mu \mathrm{mol} \mathrm{L}^{-1}$ for phosphate and $1 \mu \mathrm{mol} \mathrm{L}^{-1}$ for ammonia; 180 samples can be processed per hour and analysed.

This reliable analyser is especially useful for highresolution surface mapping of ammonia and phosphate in coastal areas and for long-term monitoring due to the low amount of reagents used in this system (Frank and Schroeder, 2007). Nitrite and nitrate underway measurements were performed using ultraviolet absorption techniques with parallel temperature and salinity corrections, thus enabling application of this approach in coastal and estuarine waters (Zielinski et al., 2011; Frank et al., 2014).

\subsection{Flow-through spectral light absorption measurements}

One of the most important biogeochemical parameters for the assessment of the environmental status of the North Sea is the phytoplankton concentration. The standard method that is 
routinely used in COSYNA is the continuous in situ measurement of chlorophyll $a$ fluorescence as a proxy for biomass estimation. Since fluorescence depends on factors such as plankton species, plankton physiology, or light climate, frequent sampling with subsequent lab analysis is necessary to reduce the large errors of up to 1 order of magnitude (UNESCO, 1980; SCOR Working Group, 1988).

Better suited to determine estimates of phytoplankton concentrations is the spectral absorption coefficient. To overcome the disturbing effects of the light scattering of inorganic and organic suspended matter, a flow-through Point-Source Integrating Cavity Absorption Meter (ft-PSICAM) was developed in COSYNA yielding continuous measurement of spectral absorption coefficients in the range of 400-710 nm with high temporal and spatial resolution. Additional useful information on CDOM/gelbstoff, algal pigments, and suspended matter can be obtained as well.

By using an integrating sphere, photons cannot get lost and the optical path length is increased, allowing the measurement of very clear waters. This PSICAM principle (Kirk, 1997; Lerebourg et al., 2002; Röttgers et al., 2005) was modified into a flow-through unit that can be used unattended on FerryBoxes or other platforms (Wollschläger et al., 2013, 2014). To reduce the contamination of the integrating sphere, it has to be cleaned automatically. The ft-PSICAM delivers data with a high temporal and spatial resolution.

\subsection{Molecular observatory}

Information on marine photosynthetic biomass distribution and biogeography with adequate temporal and spatial resolution is needed to better understand consequences of environmental change in marine ecosystems. Since COSYNA methods can only automatically measure proxy parameters for biomass, such as chlorophyll $a$, a method for the automatic determination of phytoplankton taxonomic composition is required. Molecular analyses, e.g. next-generation sequencing (NGS) or molecular sensors, are very well suited to provide comprehensive information on marine microbial or protist composition.

In COSYNA, the remotely controlled Automated Filtration System (AUTOFIM) for automated collection of samples for molecular analyses was developed. Resulting samples can either be preserved for later laboratory analyses or directly subjected to molecular surveillance of key species aboard the ship or at a monitoring side via quantitative polymerase chain reaction or an automated biosensor system (Metfies et al., 2017). The latter is based on an automated pre-treatment of the samples with an ultrasound sample preparation unit that was developed in COSYNA alongside AUTOFIM. The sampling system can either be deployed on a fixed monitoring platform or aboard a ship for nearreal-time information on abundance and distribution of phytoplankton key species. Currently, two AUTOFIM systems
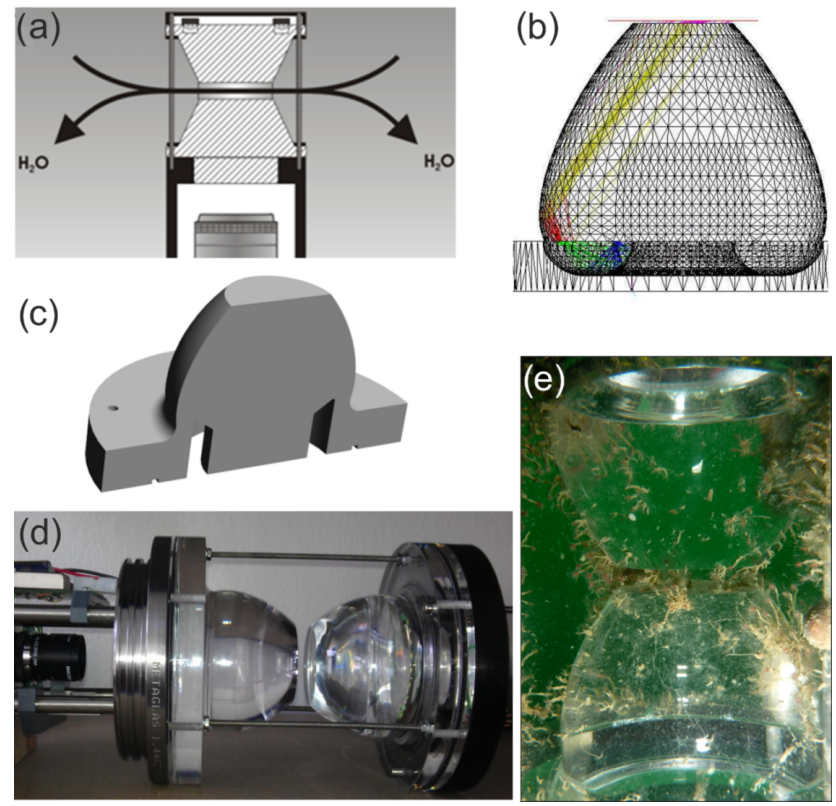

Figure 19. Design of the LOKI imaging head for moored operation. (a) Schematic overview. (b) Ray-tracing design model to investigate the best shape to increase efficiency. (c) Cross section of a 3-D model. The LEDs of the flash unit are positioned in the notch. (d) Imaging head with two optical cones: the right cone carries the circular flash unit, the left one the visual path of the camera's field of view. The camera is mounted on the left. (e) The system requires periodical cleaning in the field. The image shows bio-fouling after 5 weeks of operation in the North Sea.

are operating on Helgoland and aboard RV Polarstern in order to collect samples for molecular analyses.

\subsection{Zooplankton sampling}

In addition to phytoplankton distributions, the heterogeneities of the spatio-temporal zooplankton community assemblage are a key environmental parameter. Based on the established Lightframe On-sight Keyspecies Investigation technique (LOKI; Schulz et al., 2010), an imaging head for autonomous, moored operations was developed and attached to the COSYNA Underwater-Node System. A $360^{\circ}$-open flow chamber ensures optimal flow. The data are transferred to the shore in near real time.

LOKI combines several features bringing it close to the feasible borders set by the laws of optics (Schulz, 2013). These are an integrated flash unit providing sufficient light for short shutter times of $<30 \mu$ s to avoid motion blurring, very high resolution of $<15 \mu \mathrm{m}$ pixel $^{-1}$ to resolve fine taxonomical characteristics, and a depth of field of several millimetres. This was achieved by using two optical cones (Fig. 19e). The first one is attached to the camera housing and allows adjustment of the focal plane at a certain distance from the camera, while the tapering enhances water exchange in the flow chamber. The opposite cone houses a 

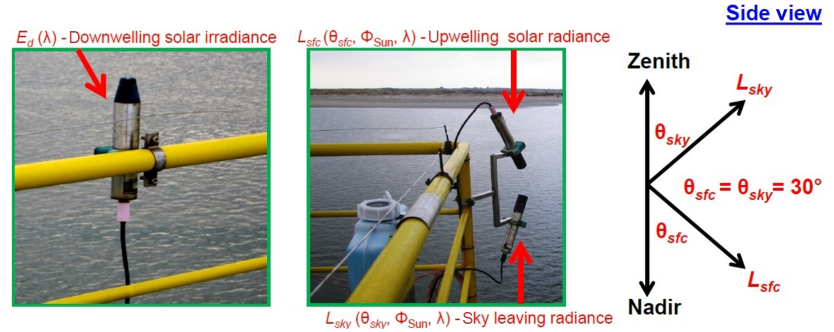

Figure 20. Set-up of RAMSES radiometers at the Spiekeroog Wadden Sea measurement pole.

high-power LED flash unit. The LEDs are arranged circular and off-axis to provide indirect and homogenous illumination resulting in high-resolution images of minute specimens and a large depth of field. The operation time is, however, limited by bio-fouling (Fig. 19).

\subsection{Active and passive sampling tools}

To determine the potential effects of micropollutants on the marine environment and biota, a set of integrative active and passive samplers has been developed. Suitable instruments for unattended use under the harsh conditions do not exist and pure concentration data of micropollutants are often not very meaningful.

For passive sampling, a Chemcatcher Metal (Petersen et al., 2015b) as well as DGTs have been used, while blue mussels (mytilus edulis sp.) have been applied as active sampling devices. After a deployment period of several weeks, the samples are analysed with conventional analytical laboratory methods. In contrast to spot sampling, passive samplers allow to measure the more representative time weighted average water concentrations (TWA). Passive sampling data also provide information about the biologically available trace element fraction of the analysed water body (Booij et al., 2016). Besides the measurement of contaminant body burdens, the application of mussels as active sampling devices allows also the analysis of potential biological effects induced by the contaminants present in the surrounding water. This is done with an analysis of the up and down regulation of specific proteins, whose expressions are related with certain detoxification mechanisms.

In COSYNA, two systems (Helmholz et al., 2015) have been developed featuring a modular design for the installation on different instrumental platforms, such as different passive sampling devices, SPM traps, and cages for biota deployment. An elevator enables the manual deployment and recovery of the experimental device at a fixed position approximately $3 \mathrm{~m}$ above the seafloor. The use of titanium reduces corrosion. The systems are deployed next to the FerryBox station in Cuxhaven at the mouth of the Elbe River and at the MARGate underwater testing site near Helgoland at a water depth of approximately $10 \mathrm{~m}$.
A continuous flow box has been developed to overcome bio-fouling problems as well as to minimise effects of changing currents on the sampling rate, as it allows integration into FerryBox systems (Petersen et al., 2015b) for passive sampling, e.g. during ship cruises to obtain TWA contaminant data. Normally, the pumped water intake system is installed at the bow of the ship's hull several metres below the sea level, thus ensuring that the sampled water body is continuously exchanged due to the movement of the ship and the water is not contaminated by the metal construction of the ship. Alternatively, a metal-free pump system can be deployed on a crane several metres away from the ship's hull.

For the calculation of uptake rates, a calibration was carried out for $\mathrm{Ni}, \mathrm{Cu}, \mathrm{Zn}, \mathrm{Cd}, \mathrm{Pb}, \mathrm{Sc}, \mathrm{Ti}, \mathrm{Mn}, \mathrm{Co}, \mathrm{Ga}, \mathrm{Sr}, \mathrm{Y}$, $\mathrm{Ba}, \mathrm{U}$, and rare earth elements under different environmental conditions (Petersen et al., 2015a). Up to now, these calibrations have not been available for most elements of environmental concern besides $\mathrm{Cu}, \mathrm{Cd}, \mathrm{Pb}, \mathrm{Ni}$, and $\mathrm{Zn}$. With these developments, a real multi-element analysis using passive sampling was possible for the first time.

\subsection{Radiometric ocean colour measurements}

The colour of the ocean is related to its optically active constituents and can be assessed with radiometric measurements within the water column and from above the water surface (Moore et al., 2009; Garaba and Zielinski, 2013a). The latter includes satellite and airborne platforms as well as measurement poles or vessels (Zielinski et al., 2009).

As part of COSYNA, the applicability of different lowaltitude hyperspectral radiometer installations was investigated. Measurement poles at Spiekeroog (Fig. 20) and in Alfacs Bay (Ebro Delta, Mediterranean) were outfitted with TriOS RAMSES hyperspectral radiometers. Underway observations were performed from research vessels Otzum and Heincke, the latter with a permanent installation of a twin remote sensing reflectance set-up to account for different sun angles along the track.

One of the major challenges is the corruption of data from sun glint and white caps. It is therefore key for any operational observing system that robust automated quality assurance methods are applied, which is achieved by parallel image acquisition and analyses (Garaba et al., 2012) or from spectral feature utilisation (J. A. Busch et al, 2013; Garaba and Zielinski, 2013b). An ensemble of sun glint detection methods improves the flagging performance of the data quality algorithm (Garaba et al., 2015a). Remote sensing spectra of good quality are used to derive in-water constituents like chlorophyll, coloured dissolved organic matter, and suspended particulate matter along cruise tracks in the North West European Shelf Sea (Garaba et al., 2014b) and Arctic (Garaba et al., 2013a), and at a time-series station in the Wadden Sea (Garaba et al., 2014a). A very recent application is the calculation of the Forel-Ule Colour Index from reflectance spectra, which opens up the possibil- 


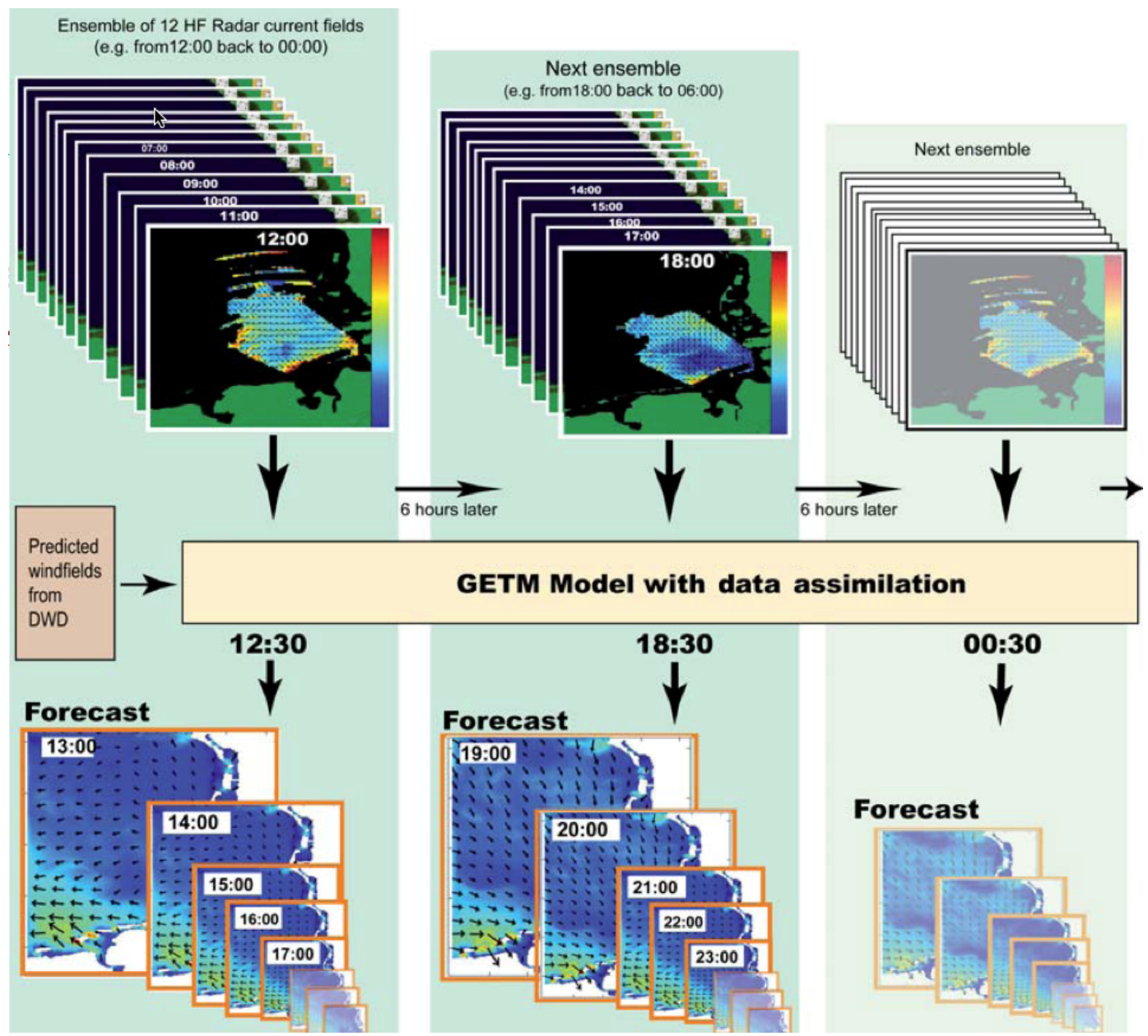

Figure 21. The functioning of data assimilation and forecasting in the pre-operational COSYNA system. HF radar system covering the German Bight. Radial current components are sent to the HZG data server, where current vectors are calculated and presented on the COSYNA data portal (Stanev et al., 2015).

ity of linking modern observations to long-term records and to involve citizens with smartphones in ocean colour measurements (J. A. Busch et al., 2016; Garaba et al., 2015b; http://www.eyeonwater.org).

\subsection{Temperature sensor for sediments}

To measure the exchange of heat and particulate matter between the German Bight and the Wadden Sea, the heat fluxes between the tidal flats and the water body have to be determined (Onken et al., 2007). As the stratification in the sediment is directly related to the heat content, the latter can easily be calculated and the heat flux between seabed and atmosphere or overlying water derived.

For these investigations, a vertical temperature sediment profiler was developed. The self-contained probe measures the temperature of intertidal sediments at depths of $0.02,0.1$, $0.2,0.3$, and $0.4 \mathrm{~m}$. Two electrodes located about $2 \mathrm{~cm}$ above the sediment indicate whether the tidal flats are wet or dry.
The probe was deployed close to the Hörnum measurement pole (Sect. 5.1.1) where seawater temperatures were measured (Onken et al., 2010).

\section{Modelling and data assimilation}

Observations - and even automated observation networks are limited by the fact that we cannot measure everywhere and at all times, which is in particular a challenge given the coastal ocean's strong variability. One of the distinguishing features of COSYNA lies therefore in the integration of observational data into models in order to close the spatial and temporal gaps of the observations and to calculate energy or matter fluxes (Stanev at al., 2016). Model studies are also essential for identifying regions with high sensitivity or variability in certain quantities that warrant the deployment of measurement devices. On the other hand, state-of-the-art numerical models of coastal dynamics require monitoring data 


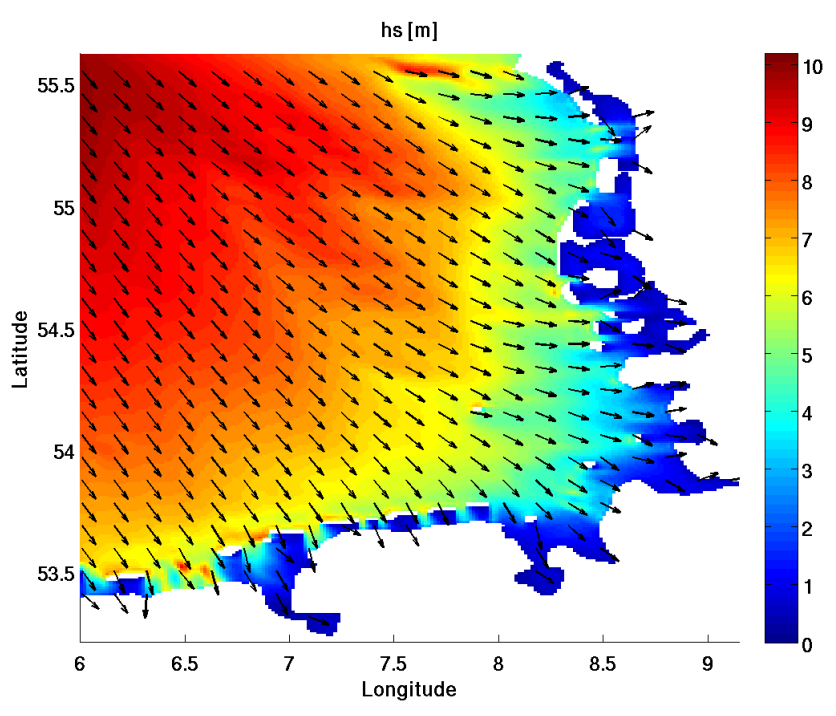

Figure 22. Significant wave height calculated for the German Bight on 1 November 2006 with the WAM wave model used in COSYNA.

to reasonably manage large model uncertainties. The observations are used to bring models closer to the "real" state of the ocean, either by verifying model output or by assimilating them into models. These data sets should be representative and coherent. In order to continuously provide accurate pre-operational coastal ocean state estimates and forecasts, COSYNA integrates near-real-time measurements into numerical models in a pre-operational way that is meant to improve both historical model runs and forecasts.

In this context, COSYNA has explored different techniques to assimilate data into models. Satisfactory assimilation results were achieved when 2-D data fields were available, such as derived from HF radar or satellite observations (Stanev et al., 2015) providing a $12 \mathrm{~h}$ forecast. The assimilation of data from single locations or sections usually only influences the immediate vicinity of the locations where the observations were made and has limited value for greater spatial extensions (Grayek et al., 2011; Stanev et al., 2011). Data assimilation based on physical values is generally more easily achieved than with biogeochemical quantities. The successful assimilation products of COSYNA encompass surface currents, significant wave height, period and wave direction, as well as temperature.

For the assimilation of current observations, a nested 3-D hydrodynamic model is used. In situ current time series are measured with stationary ADCPs at the FINO-1 and FINO3 research platforms. Remote sensing of surface currents is carried out with three HF radar systems installed in the German Bight (Sect. 5.3). For technical details of data processing and accuracy see Stanev et al. (2015). The flow of observational data including observing nodes, data management system, and data assimilation capabilities is streamlined toward
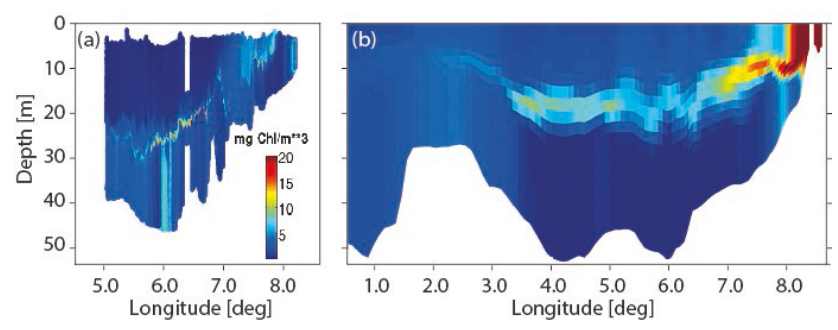

Figure 23. Chlorophyll transects around $55^{\circ} 15^{\prime}$ latitude in the German Bight (a) observed with a Scanfish in July 2010 (Sect. 5.9) and (b) as result of a coupled GETM and an adaptive ecosystem model showing a 1-week mean (Wirtz and Kerimoglu, 2017).

meeting the needs for high-quality operational data products in the German Bight (Fig. 21).

Although there are hundreds of HF radar systems installed worldwide, their operational use in numerical models, in particular at sub-tidal periods, is not well established. The assimilation of HF radar data is a challenge due to irregular data gaps in time and space, inhomogeneous observational errors, as well as inconsistencies between boundary forcing and observations. Furthermore, due to the high sampling frequency of typically several times per hour, it is difficult for the model to reach equilibrium between two time steps. Therefore, the Spatio-Temporal Optimal Interpolation (STOI) filter has been developed by Stanev et al. (2015). It enables a blending of model simulations from a free run and radar observations by extending the classical Kalman analysis method to time periods of at least one tidal cycle by using the Kalman analysis equation.

The modelling suite is based on the General Estuarine Transport Model (GETM; Burchard and Bolding, 2002) 3D primitive equation. It is used in two configurations: a North Sea-Baltic Sea model of $5.6 \mathrm{~km}$ resolution and a oneway nested German Bight model with a horizontal resolution of about $1 \mathrm{~km}$ (Stanev et al., 2011). Both models use terrain-following equidistant vertical coordinates (s coordinates) with 21 non-intersecting layers.

The validation of the model and the physical interpretation of the results showed the good skills of STOI not only in the area covered by HF radar observations, but also outside it, revealing its upscaling capabilities (Stanev et al., 2015). By using HF radar data in the STOI system, homogeneous and continuous 2-D current fields were thus generated over the entire model area. The quality is superior to a free model run, demonstrating that data assimilation can enhance coastal ocean prediction capabilities by making use of observations and modelling, which is an essential aspect of an operational system. The combination of HF radar data and numerical model results can therefore also provide a deeper insight into the German Bight dynamics and provide useful indications of where further model developments (improvements) are needed. 
COSYNA also provides a pre-operational wave forecast based on the WAM Cycle 4 wave model (release WAM 4.5.3; Komen et al., 1994; Günther et al., 1992). The computational system consists of a regional WAM for the North Sea with a spatial resolution of $\sim 5 \mathrm{~km}$ and a nested grid with a spatial resolution of $900 \mathrm{~m}$ for the German Bight. Wind fields and boundary information are provided by the German Weather Service (DWD) derived from their regional wave model EWAM. A number of wave parameters such as significant wave height, period, and total wave direction are calculated (Staneva et al., 2015). It has continuously provided hindcasts and forecasts since December 2009. Daily at 00:00 and 12:00 UTC, a $24 \mathrm{~h}$ regional forecast is issued for the North Sea and a local one for the German Bight. As an example, a typical wave height distribution with low values close to the coasts and higher values offshore is shown for the German Bight for 1 November 2006 (Fig. 22).

A combination of biogeochemical observational data and numerical models in COSYNA has been instrumental for a better understanding of material dynamics including steep cross-shore gradients ranging from shallow near-shore waters to the continental shelf, strong lateral gradients and mesoscale patchiness, as well as singular events, such as storms or ice winters. These processes are intimately linked to the functioning of coastal ecosystems but also affect efforts to maintain shipping pathways and coastal defense, as well as water quality.

A model- and data-based analysis (März et al., 2016) highlights a remarkable cross-shore separation of the coastal ocean with a maximum settling velocity of suspended material in the transition zone between the shallow Wadden Sea and the continental shelf, which modifies the traditional concept of continuous gradients. This acceleration of vertical deposition fluxes is likely due to enhanced particle aggregation induced by organic substances, which in turn are released by planktonic microorganisms ( $\mathrm{Su}$ et al., 2015; Hofmeister et al., 2017). Enhanced deposition in the coastal transition zone is accounting for an effective trapping of lithogenic material within near-shore waters, while it may act as a barrier for offshore organic particles. Even higher variability at scales below the cross-shore gradients is evident in COSYNA lander observations (Sect. 5.6) of total benthic oxygen consumption.

Using an ecosystem model that includes turbidity fields, estimated from Scanfish observations (Sect. 5.9), and that accounts for the acclimation capacity of phytoplankton, spatial variability in chlorophyll $a$ can be reproduced to a high degree (Fig. 23; Wirtz and Kerimoglu, 2017). Previous modelling attempts such as of van Leeuwen et al. (2013) or Schrum et al. (2006) do not capture the extreme vertical squeezing of chlorophyll $a$ within thin layers, which may affect model-derived estimates of total primary production. Our new model results also reveal how reconstructed pelagic patterns decouple from benthic respiration patterns. Vertical deposition of freshly produced material greatly varies within the coastal ocean. In a few, mostly deeper regions, deposition prevails over resuspension, leading to depositional hotspots (Wirtz and Kerimoglu, 2017).

Vertical structures in nutrient concentrations are key to understanding whether, when, and where phytoplankton blooms form after storm events (Su et al., 2015). Vertical structures in chlorophyll $a$ below the metre scale (thin layers) as recently observed by gliders and Scanfish (Sects. 5.2 and 5.9) as a persistent feature indicate that a considerable amount of primary production takes place unnoticed from satellite observations. To include these vertical patterns in modelling studies requires sophisticated formulations like those by Riegman and Colijn (1991), Behrenfeld and Falkowski (1997), and Behrenfeld et al. (2005). For the German Bight model validations, using COSYNA data can help to significantly improve estimates of total primary production.

\section{Data management and data products}

\subsection{Data management}

The COSYNA data management system (CODM) was established to make observational and model data publicly available in near-real time (Breitbach et al., 2016). The time between observations and the availability of data on CODM ranges from a few minutes for stationary measurements to about $24 \mathrm{~h}$ for data obtained from ships of opportunity and satellites.

Due to the various observational platforms and model output, it is a significant challenge to provide a comprehensive overview of the observations with their diverse data formats in terms of parameters, dimensionality, and observational methods. It is achieved by describing the data using metadata and by making all data available for different analyses and visualisations in a combined way independent of data dimensionality. This concerns in particular the presentation of different data types together in one plot, such as the mapping of the same variable derived from satellite imagery and in situ observations. Key for this is the harmonisation of parameter names. The various internally used parameter names for the same observed property are mapped to the corresponding Climate and Forecast (CF) standard name (Eaton et al., 2010).

Another important aspect of CODM is the use of standardised metadata that are adapted for the use in direct web service requests (Fig. 24). Two types of metadata are used in CODM: For observations, the first type describes an observational platform, its sensors, and observed properties, the second type describes the observed data.

The metadata are created automatically if the data sets have a distinct beginning and ending. Examples are ship or glider transects, or single satellite scenes. For stationary platforms, only one metadata record is created for the entire time series. For models, the first type of metadata describes the 


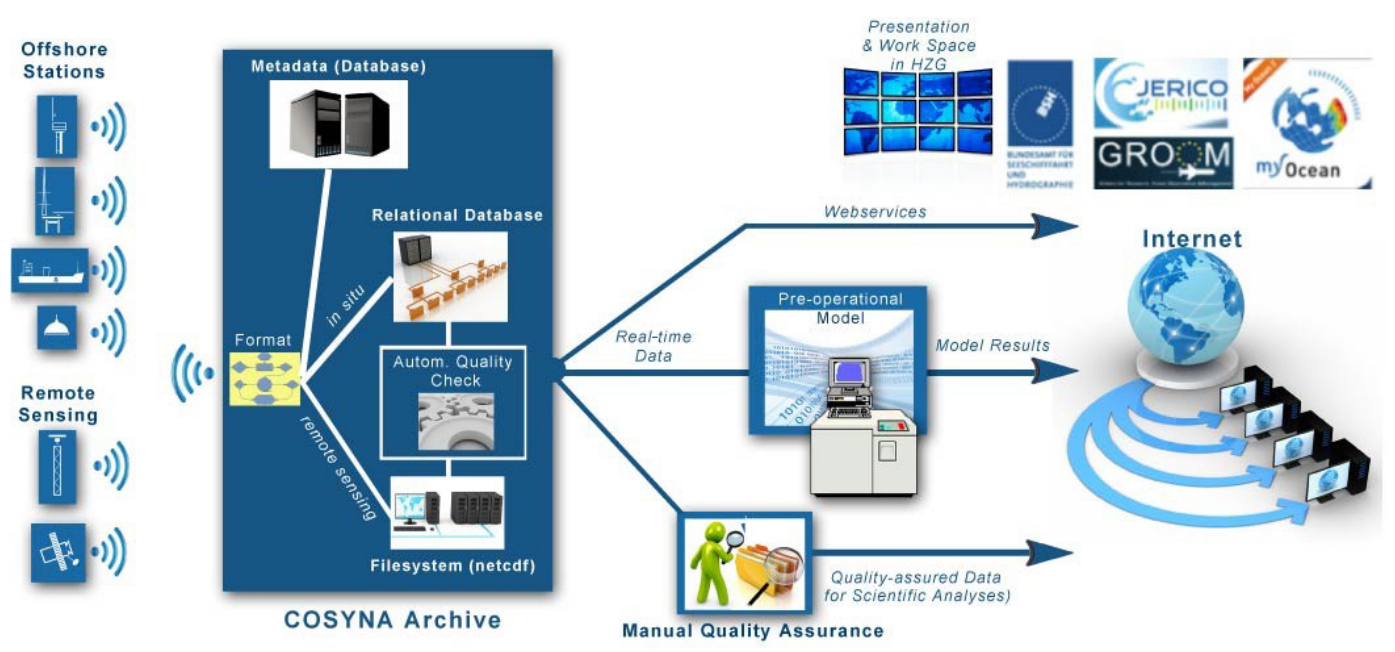

Figure 24. Data flow in COSYNA.

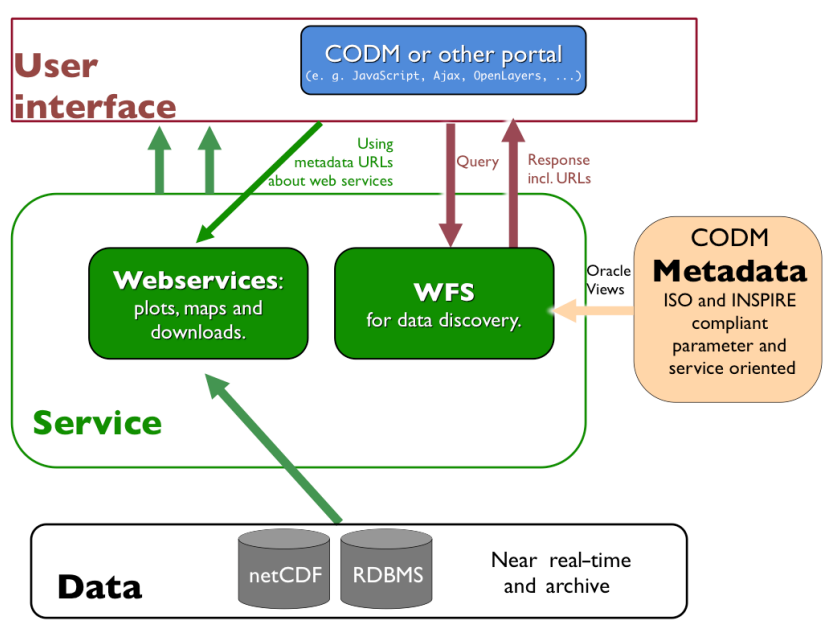

Figure 25. Data management architecture: the connection between the user interface on the one hand and data or metadata on the other hand is handled solely by web services like Web Feature Services (WFS) or Web Map Services (WMS).

model itself, while the second type describes the model run. Data-metadata are ISO19115 and INSPIRE compliant (EC Directive, 2007) and contain all necessary information to access the data as download, plot, or map. The metadata themselves are also mapped to the Web Feature Service (Fig. 25).

The observational data have to pass a number of automated and supervised tests before they become publicly accessible in the data portal. Depending on the test results for range, stuck values, spikes, and - for some parameters - gradients, quality flags are assigned to the data. The procedures and quality flags are in line with international guidelines (Breitbach et al., 2016; SeaDataNet, 2010).

CODM is a publicly available Open Data portal. There are no restrictions or fees for downloading and using the data,

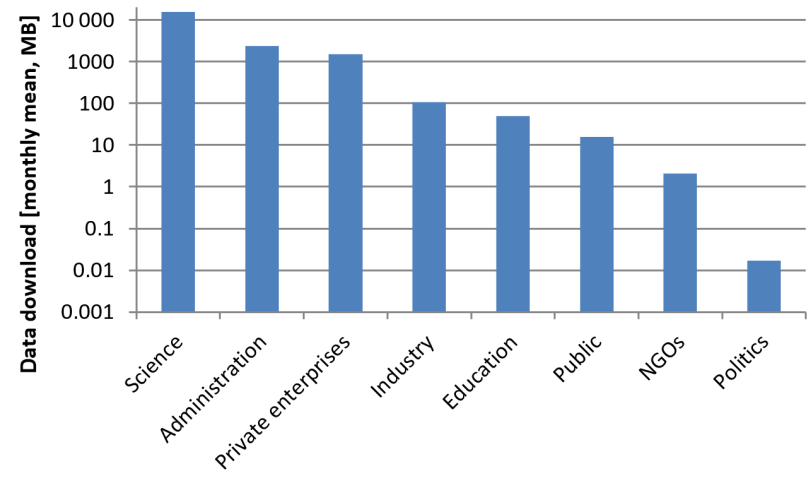

Figure 26. Mean monthly data use for different categories of users. Data are shown for the time period between November 2014, when the user registration started, and January 2016.

but CODM requires a basic user registration. Users are asked to provide country of origin, a user category, and the city. No other personal information is mandatory. Users are also asked to acknowledge COSYNA as a data source in their publications. The majority of users are in the science sector, followed by administration (Fig. 26).

\subsection{Data products}

COSYNA is monitoring the current state of the coastal system in the North Sea and is generating modelled preoperational state reconstructions and forecasts. These routinely provided data can be grouped into four "product" categories.

a. High-resolution time series at fixed positions. Meteorological, oceanographic, water quality, and biological parameters are continuously observed at measuring poles (Sect. 5.1) Spiekeroog, Hörnum Deep, and Elbe, research platform FINO3 (Sect. 5.1.2), and at the station- 
ary FerryBox systems in Cuxhaven and on Helgoland (Sect. 5.4).

b. Repeated transects. Oceanographic and biogeochemical parameters are measured during regular ship and glider surveys (Sects. 5.2, 5.9) and with automated FerryBox systems on ships of opportunity (Sect. 5.4).

c. Remote sensing information. Regular maps of currents, chlorophyll distribution, and optical seawater properties are obtained with remote sensing by HF radar (Sect. 5.3) and satellites (Sect. 5.7). The data cover large areas of the German Bight and are integrated with observational in situ data.

d. Integrated COSYNA products. The automatically produced data fields of the German Bight are continuous in space and time and provide hindcast, nowcast, and short-term forecasts. The latter two are improved with data assimilation procedures (Sect. 7).

The COSYNA product, "Surface Current Fields", provides data fields and maps of tidal hindcasts and forecasts of sea surface currents in the German Bight. The fields are updated every $30 \mathrm{~min}$. They are created by assimilating regular $\mathrm{HF}$ radar measurements into a 3-D circulation model (Stanev et al., 2011, 2015; Sect. 7).

The pre-operational COSYNA wave forecast model system runs twice a day and provides a $72 \mathrm{~h}$ forecast on the regional scale for the North Sea and on the local scale for the German Bight. Significant wave height, period, and total wave direction are calculated (Staneva et al., 2014).

In order to provide the spatial distribution of sea surface temperature and salinity in the North Sea, FerryBox observations taken along ship tracks are extrapolated to larger areas combining them with information from numerical models. Data from the Cuxhaven-Immingham route are assimilated into a 3-D circulation model every $24 \mathrm{~h}$ (Grayek et al., 2011).

\section{Outreach and stakeholder interaction}

COSYNA aims to make scientific data, results, and data products publicly available by reaching out to different target groups and users, such as the scientific community, potential users in business enterprises and authorities, and the general public. To serve this purpose, COSYNA publishes several print products in German and English that are publicly available for download at the COSYNA website, or that can be ordered. Flyers and more comprehensive brochures provide an overview of the goals, approaches, activities, and results of COSYNA. The annual progress reports are intended for COSYNA partners and users and describe selected results and activities of the various working groups and subprojects within COSYNA. Newsletter and product fact sheets provide COSYNA partners and users as well as interest groups or the general public with information on activities, events, or data products.

COSYNA maintains the website http://www.cosyna.de that informs about motivation, approach, observations, modelling, products, and outreach activities. The COSYNA data portal is linked to that website and provides access to data download and visualisation. On average, the COSYNA website has been visited by more than 500 different external visitors per month.

Furthermore, COSYNA has developed an interactive app with versions for iPad and other tablet PCs as well as Android- and iOS-based smartphones. The app provides explanatory texts and pictures describing the observing systems, instruments, models, and products, as well as the COSYNA partners. Near-real-time data for several platforms are available. COSYNA also presents the app in permanent exhibits in museums, or temporarily at public events or trade shows.

It is one of the main goals of COSYNA to bridge the gap between operational oceanography and the users of marine data in local authorities, non-governmental organisations, science, and industry. In order to ensure that products are applicable, COSYNA has been initiating a dialogue with stakeholders, allowing for direct feedback and input to COSYNA. In the initial phase of COSYNA, a national and an international survey showed that the COSYNA data products are useful to a great number of users from different sectors and fit into the international context. Follow-up workshops and an external evaluation of the Surface Current Fields integrated COSYNA product have clearly improved COSYNA products and their usability. To explore the streamlining of COSYNA products for the offshore wind energy industry, several workshops were held to pave the way for future co-operation with offshore wind energy companies (Eschenbach, 2017).

\section{Conclusions and outlook}

COSYNA was established with its sights on understanding the state and variability of complex interdisciplinary processes in the North Sea and the Arctic. During its first years, work concentrated on establishing the observational network, developing sensors and numerical models, testing and applying data assimilation techniques, building a data management system and testing outreach strategies. Now that the core of what had been envisioned in the original concepts is operational and functioning, COSYNA will expand into new areas, spatially as well as scientifically.

Currently, COSYNA is being extended to the western part of the Baltic Sea (in cooperation with a new partner, GEOMAR, Helmholtz Centre for Ocean Research) by installing an Underwater-Node System in spring 2016 in the Eckernförde Bight near the location of GEOMAR's long established Boknis Eck time-series station (Lennartz et al., 2014). COSYNA already contributes to observations of other 
coastal areas in the world, such as the Lena delta, the Bohai Sea in China, or with instruments on research vessels and cruise ships operating in various parts of the world ocean. In the long run, COSYNA will be part of HZG's Global Coast project that aims at identifying representative coastal regions worldwide that will help evaluate the role of coastal areas for global processes, while using a global context for understanding regional and coastal processes.

To this end and for use in large national and international research projects, COSYNA plans to develop mobile observing systems with high-resolution capabilities in space and time that have very short deployment times in order to be able to react to extreme events such as storms and floods. As the focus of research projects will be shifting more and more to an integrated understanding of complex systems, this approach will require cooperation with partners in the atmospheric and terrestrial research communities. In the future, COSYNA will be closely interlinked with the Elbe River supersite of DANUBIUS, the most recent European ESFRI Roadmap project studying river-delta-sea systems, and will be part of the Helmholtz Association's MOSES (Modular Observing System for the Earth System) research infrastructure.

Intensified modelling efforts, especially regarding biogeochemical models and data assimilation, are needed to put the COSYNA observations in a broad context and help understand coastal systems. This will also yield future data products including wind fields, ship detection, and biogeochemical parameters. Chlorophyll maps and maps of suspended particulate matter will be obtained from satellites on a regular basis. The assimilation of other quantities is a work in progress and will be published when they become available.

The successful technology development of underwater nodes will continue. Currently, experiments with smaller, more flexible units are underway. Alternative forms of power supplies, such as fuel cells, are being tested and may allow for a flexible network of nodes.

New partners are joining COSYNA: GEOMAR in Kiel and the Franzius Institute for Hydraulic, Estuarine, and Coastal Engineering at the University of Hannover have recently agreed to become COSYNA partners. For the future, discussions with international partners will be sought and international cooperation will be intensified - in particular with the countries bordering the North Sea.

While COSYNA has evolved into a well-established integrated pre-operational observing system, research will become more central to defining COSYNA's endeavours. Utilising the combined expertise of its various partner institutions, COSYNA's science foci will include biogeochemical cycles from rivers to the North Sea and the North Atlantic, the role of wind farms for physical, biogeochemical, and biological processes in the coastal ocean as well as associated engineering questions, land-Wadden Sea-North Sea exchange processes with an extensive experiment spanning from the Netherlands along the German coast to Denmark in- volving physics and biogeochemistry, and exploration of the possibilities and challenges associated with citizen science.

Data availability. All COSYNA data are available free of charge at the COSYNA data portal (www.cosyna.de).

Competing interests. The authors declare that they have no conflict of interest.

Acknowledgements. COSYNA was implemented between 2010 and 2014. The infrastructure and instrumentation of COSYNA was funded by the German Federal Ministry of Education and Research through the Helmholtz Association. COSYNA is developed and operated jointly between 11 partner institutions entirely contributing personnel and funding for development, operation, and maintenance. COSYNA is coordinated by the HelmholtzZentrum Geesthacht. Currently, funding is available through the Advanced Remote Sensing - Ground Truth Demo and Test Facilities (ACROSS) infrastructure of the Helmholtz Association.

The implementation and operation of COSYNA would not have been possible without the competent and tireless efforts of the technical staff at all involved institutions. We thank the master and the crew of RV Heincke for their help and support during the ship cruises. The cruises were conducted under grant numbers AWI_HE298_00, AWI_HE303_00, AWI_HE308_00, AWI_HE312_00, AWI_HE319_00, AWI_HE325_00, AWI_HE331_00, AWI_HE336_00, AWI_HE353_00, AWI_HE359_00, AWI_HE365_00, AWI_HE371_00, AWI_HE391_00, AWI_HE397_00, AWI_HE407_00, AWI_HE412_00 AWI_HE417_00, AWI_HE441_00, and AWI_HE447_00.

The article processing charges for this open-access publication were covered by a Research Centre of the Helmholtz Association.

Edited by: P. Testor

Reviewed by: two anonymous referees

\section{References}

ABARE: Economics of Australia's sustained ocean observing system, benefits and rationale for public funding, The Australian Bureau of Agricultural and Resource Economics and Economic Consulting Services, Report 44, 2006.

Ahmerkamp, S., Winter, C., Janssen, F., Kuypers, M. M. M., and Holtappels, M.: The impact of bedform migration on benthic oxygen fluxes, J. Geophys. Res.-Biogeo., 120, 2229-2242, doi:10.1002/2015JG003106, 2015.

Ahmerkamp, S., Winter, C., Krämer, K., de Beer, D., Janssen, F., Kuypers, M. M. M., and Holtappels, M.: Regulation of benthic oxygen fluxes in permeable sediments of the coastal ocean, Limnol. Oceanogr., doi:10.1002/?lno.10544, 2017. 
Amirshahi, S. M., Winter, C., and Kwoll, E.: Characteristics of instantaneous turbulent events in southern German Bight, in: River Flow, 2016.

Aßmann, S.: Entwicklung und Qualifizierung autonomer Messsysteme für den $\mathrm{pH}$-Wert und die Gesamtalkalinität von Meerwasser, PhD-Thesis, Christian-Albrechts-University, Kiel, 2012.

Aßmann, S., Frank, C., and Körtzinger, A.: Spectrophotometric high-precision seawater $\mathrm{pH}$ determination for use in underway measuring systems, Ocean Sci., 7, 597-607, doi:10.5194/os-7597-2011, 2011.

Badewien, T. H., Zimmer, E., Bartholoma, A., and Reuter, R.: Towards continuous long-term measurements of suspended particulate matter (SPM) in turbid coastal waters, Ocean Dynam., 59, 227-238, doi:10.1007/S10236-009-0183-8, 2009.

Behrenfeld, M. J. and Falkowski, P. G.: Photosynthetic Rates Derived from Satellite-Based Chlorophyll Concentration, Limnol. Oceanogr., 42, 1-20, 1997.

Behrenfeld, M. J., Boss, E., Siegel, D. A., and Shea, D. M.: Carbon-based ocean productivity and phytoplankton physiology from space, Global Biogeochem. Cy., 19, GB1006, doi:10.1029/2004GB002299, 2005.

Bell, P. S. and Thorne, P. D.: Application of a high resolution acoustic scanning system for imaging sea bed microtopography, Seventh International Conference on Electronic Engineering in Oceanography, Tech. Trans. Res. Ind., 128-133, doi:10.1049/cp:19970673, 1997.

Booij, K., Robinson, C. D., Burgess, R. M., Mayer, P., Roberts, C. A., Ahrens, L., Allan, I. J., Brant, J., Jones, L., Kraus, U. R., Larsen, M. M., Lepom, P., Petersen, J., Pröfrock, D., Roose, P., Schäfer, S., Smedesp, F., Tixier, C., Vorkamp, K., and Whitehouse, P.: Passive Sampling in Regulatory Chemical Monitoring of Nonpolar Organic Compounds in the Aquatic Environment, Environ. Sci. Technol., 50, 3-17, doi:10.1021/acs.est.5b04050, 2016.

Borges, A. V.: Do we have enough pieces of the jigsaw to integrate $\mathrm{CO}_{2}$ fluxes in the coastal ocean?, Estuaries, 28, 3-27, doi:10.1007/BF02732750, 2005.

Brand, M. and Fischer, P.: Species composition and abundance of the shallow water fish community of Kongsfjorden, Svalbard, Polar Biol., 39, 1-13, doi:10.1007/s00300-016-2022-y, 2016.

Breitbach, G., Krasemann, H., Behr, D., Beringer, S., Lange, U., Vo, N., and Schroeder, F.: Accessing diverse data comprehensively - CODM, the COSYNA data portal, Ocean Sci., 12, 909-923, doi:10.5194/os-12-909-2016, 2016.

Bruno, L., Braca, P., Horstmann, J., and Vespe, M.: Experimental Evaluation of the Range-Doppler Coupling on HF Surface Wave Radar, IEEE Geosci. Remote S., 10, 4, 850-854, doi:10.1109/LGRS.2012.2226203, 2013.

Burchard, H. and Badewien, T. H.: Thermohaline circulation of the Wadden Sea, Ocean Dynam., 65, 1717-1730, doi:10.1007/s10236-015-0895-x, 2015.

Burchard, H. and Bolding, K.: GETM: A general estuarine transport model. European Commission Joint Research Centre Tech. Rep. EUR 20253 EN, 157, 2002.

Burchard, H., Flöser, G., Staneva, J. V., Badewien, T. H., and Riethmüller, R.: Impact of Densitiy Gradients on Net Sediment Transport into the Wadden Sea, J. Phys. Oceanogr., 38, 566-587, doi:10.1175/2007JPO3796.1, 2008.
Busch, J., Price, I., Jeauson, E., Zielinski, O., and v.d. Woerd, H. J.: Citizens and satellites: Assessment of phytoplankton dynamics in a NW Mediterranean aquaculture zone, Int. J. Appl. Earth Obs., 47, 40-49, doi:10.1016/j.jag.2015.11.017, 2016.

Busch, J. A., Hedley, J. D., and Zielinski, O.: Correction of hyperspectral reflectance measurements for surface objects and direct sun reflection on surface waters, Int. J. Remote Sens., 34.2013, 19, 6651-6667, doi:10.1080/01431161.2013.804226, 2013.

Busch, M., Kannen, A., Garthe, S., and Jessopp, M.: Consequences of a cumulative perspective on marine environmental impacts: offshore wind farming and seabirds at North Sea scale in context of the EU Marine Strategy Framework Directive, Ocean Coast. Manage., 71, 213-224, doi:10.1016/j.ocecoaman.2012.10.016, 2013.

Buschbaum, C., Lackschewitz, D., and Reise, K.: Nonnative macrobenthos in the Wadden Sea ecosystem, Ocean Coast. Manage. 68, 89-101, doi:10.1016/j.ocecoaman.2011.12.011, 2012.

Carder, K. L., Hawes, D. K., Baker, K. A., Smith, R. C., Steward, R. G., and Mitchell, B. G.: Reflectance model for quantifying chlorophyll $\mathrm{a}$ in the presence of productivity degradation products, J. Geophys. Res., 96, 20599-20611, doi:10.1029/91JC02117, 1991.

Carpenter, J. R., Merckelbach, L., Callies, U., Clark, S., Gaslikova, L., and Baschek, B.: Potential Impacts of Offshore Wind Farms on North Sea Stratification, PLoS ONE, 11, e0160830, doi:10.1371/journal.pone.0160830, 2016.

Chen, C. T. A. and Borges, A. V.: Reconciling opposing views on carbon cycling in the coastal ocean: continental shelves as sinks and near-shore ecosystems as sources of atmospheric $\mathrm{CO}_{2}$, Deep-Sea Res. Pt. II, 56, 8-10, 578-590, doi:10.1016/j.dsr2.2009.01.001, 2009.

Colijn, F. and de Jonge, V. N.: Primary production of microphytobenthos in the Ems_Dollard estuary, Mar. Ecol.-Progr. Ser., 14, 185-196, 1984.

Constantinescu, G., Garcia, M., and Hanes, D. (Eds.): Taylor \& Francis Group, Boca Raton, FL CRC Press 2016, 175-182, ISBN: 978-1-138-02913-2, ISBN: 978-1-317-28912-8, 2016.

Cottier, F., Tverberg, V., Inall M., Svendsen, H., Nilsen, F., and Griffiths, C.: Water mass modification in an Arctic fjord through cross-shelf exchange: The seasonal hydrography of Kongsfjorden, Svalbard, J. Geophys. Res., 110, C12005, doi:10.1029/2004JC002757, 2005.

Dittmann, S. (Ed.): The Wadden Sea Ecosystem: stability properties and mechanism, Springer Berlin Heidelberg, ISBN: 978-3-64264256-2, doi:10.1007/978-3-642-60097-5, 1999.

Doerffer, R. and Schiller, H.: The MERIS Case 2 water algorithm, Int. J. Remote Sens., 28, 517-535, doi:10.1080/01431160600821127, 2007.

Dore, J. E., Lukas, R., Sadler, D. W., Church, M. J., and Karl, D. M.: Physical and biogeochemical modulation of ocean acidification in the central North Pacific, P. Natl. Acad. Sci. USA, 106, 12235 12240, doi:10.1073/pnas.0906044106, 2009.

Drücker, S., Steglich, D., Merckelbach, L., Werner, A., and Bargmann, S.: Finite element damage analysis of an underwater glider-ship collision, J. Mar. Sci. Technol., 1-10, doi:10.1007/s00773-015-0349-7, 2015.

Dzvonkovskaya, A., Gurgel, K.-W., Rohling, H., and Schlick, T.: Low power high frequency surface wave radar application for 
ship detection and tracking, Proc. Int. Conf. Radar, Adelaide, SA, 627-632, doi:10.1109/RADAR.2008.4653998, 2008.

Eaton, G., Drach, T., and Hankin, S.: netCDF Climate and Forecast (CF) Metadata Conventions, Version 1.5, available at: http://cfconventions.org/Data/cf-conventions/cf-conventions- 1 . 5/build/cf-conventions.html (last access: May 2017), 2010.

EC Directive: Directive 2007/2/EC of the European Parliament and of the Council of 14 March 2007 establishing an Infrastructure for Spatial Information in the European Community, available at: http://eurlex.europa.eu/LexUriServ/LexUriServ.do? uri=OJ:L:2007:108:0001:0014:EN:PDF (last access: May 2017), 2007.

Emeis, K.-C., van Beusekom, J., Callies, U., Ebinghaus, R., Kannen, A., Kraus, G., Kröncke, I., Lenhart, H., Lorkowski, I., Matthias, V., Möllmann, C., Pätsch, J., Scharfe, M., Thomas, H., Weisse, R., and Zorita, E.: The North Sea A shelf sea in the Anthropocene, J. Mar. Syst., 141, 18-33, doi:10.1016/j.jmarsys.2014.03.012, 2015.

Eschenbach, C. A.: Bridging the gap between observational oceanography and users, Ocean Sci., 13, 161-173, doi:10.5194/os-13-161-2017, 2017.

Feely, R. A., Doney, S. C., and Cooley, S. R.: Ocean acidification: Present conditions and future changes in a high- $\mathrm{CO}_{2}$ world, Oceanogr., 22, 36-47, doi:10.5670/oceanog.2009.95, 2009.

Fischer, P., Schwanitz, M., Loth, R., Posner, U., Brand, M., and Schröder, F.: First year of practical experiences of the new Arctic AWIPEV-COSYNA cabled Underwater Observatory in Kongsfjorden, Spitsbergen, Ocean Sci., 13, 259-272, doi:10.5194/os13-259-2017, 2017.

Flöser, G., Burchard, H., and Riethmüller, R.: Observational evidence for estuarine circulation in the German Wadden Sea, Cont. Shelf Res., 31, 1633-1639, doi:10.1016/j.csr.2011.03.014, 2011.

Frank, C. and Schroeder, F.: Using Sequential Injection Analysis to Improve System and Data Reliability of Online Methods: Determination of Ammonium and Phosphate in Coastal Waters, J. Autom. Method. Manag., 49535, doi:10.1155/2007/49535, 2007.

Frank, C., Schroeder, F., Ebinghaus, R., and Ruck, W.: A Fast Sequential Injection Analysis System for the Simultaneous Determination of Ammonia and Phosphate, Microchim. Ac., 154, 3138, doi:10.1007/s00604-006-0496-y, 2006.

Frank, C., Meier, D., Voss, D., and Zielinski, O.: Computation of nitrate concentrations in coastal waters using an in situ ultraviolet spectrophotometer: Behavior of different computation methods in a case study a steep salinity gradient in the southern North Sea, Meth. Oceanogr., 9, 34-43, doi:10.1016/j.mio.2014.09.002, 2014.

Friedrich, J., van Beusekom, J. E. E., Neumann, A., Naderipour, C., Janssen, F. Ahmerkamp, S., Holtappels, M., and Krämer, K.: Long-term impact of bottom trawling on pelagic-benthic coupling inthe southern North Sea (German Bight), EGU201615791, 2016.

Furness, R. W. and Camphuysen, C. J.: Seabirds as monitors of the marine environment, ICES J. Mar. Sci., 54, 726-737, doi:10.1006/jmsc.1997.0243, 1997.

Garaba, S. P. and Zielinski, O.: Comparison of remote sensing reflectance from above-water and in-water measurements west of Greenland, Labrador Sea, Denmark Strait, and west of Iceland, Opt. Expr., 21, 15938-15950, doi:10.1364/OE.21.015938, 2013a.
Garaba, S. P. and Zielinski, O.: Methods in reducing surface reflected glint for shipborne above-water remote sensing, J. Eur. Opt. Soc.-Rapid, 8, 1-8, doi:10.2971/jeos.2013.13058, 2013 b.

Garaba, S. P., Schulz, J., Wernand, M. R., and Zielinski, O.: Sunglint detection for unmanned and automated platforms, Sensors 12, 12545-12561, doi:10.3390/s120912545, 2012.

Garaba, S. P., Badewien, T. H., Braun, A., Schulz, A.-C., and Zielinski, O.: Using ocean colour remote sensing products to estimate turbidity at the Wadden Sea time series station Spiekeroog, J. Eur. Opt. Soc.-Rapid, 9, 1-6, doi:10.2971/jeos.2014.14020, 2014a.

Garaba, S. P., Voß, D., and Zielinski, O.: Physical, bio-optical state and correlations in North-Western European Shelf Seas, Remote Sens., 6, 5042-5066, doi:10.3390/rs6065042, 2014b.

Garaba, S. P., Friedrichs, A., Voss, D., and Zielinski, O.: Classifying natural waters with Forel-Ule Colour Index System: Results, Applications, Correlations and Crowdsourcing, Intl. J. Environ. Res. Publ. Health, 12, 16096-16109, doi:10.3390/ijerph121215044, 2015a.

Garaba, S. P., Voß, D., Wollschläger, J., and Zielinski, O.: Modern approaches to shipborne ocean colour remote sensing, Appl. Opt., 54, 3602-3612, doi:10.1364/AO.54.003602, 2015b.

Garthe, S. and Hüppop, O.: Scaling possible adverse effects of marine wind farms on seabirds: developing and applying a vulnerability index, J. Appl. Ecol., 41, 724-734, doi:10.1111/j.00218901.2004.00918.x, 2004.

Garthe, S., Peschko, V., Kubetzki, U., and Corman, A.-M.: Seabirds as samplers of the marine environment - a case study in Northern Gannets, Ocean Sci., submitted, 2017.

Gohin, F., Druon, J. N., and Lampert, L.: A five channel chlorophyll concentration algorithm applied to SeaWiFS data processed by SeaDAS in coastal waters, Int. J. Remote Sens., 23, 8, 16391661, doi:10.1080/01431160110071879, 2002.

Gollasch, S., Haydar, D., Minchin, D., Wolff, W. J., and Reise, K.: Introduced aquatic species of the North Sea coasts and adjacent brackish waters, in: Biological Invasions in Marine Ecosystems, edited by: Rilov, G. and Crooks, J. A., Ecological Studies, 204, 507-528, doi:10.1007/978-3-540-79236-9_29, 2009.

Grashorn, S., Lettmann, K. A., Wolff, J.-O., Badewien, T. H., and Stanev, E. V.: East Frisian Wadden Sea hydrodynamics and wave effects in an unstructured-grid model, Ocean Dynam., 65, 419434, doi:10.1007/s10236-014-0807-5, 2015.

Grayek, S., Staneva, J., Schulz-Stellenfleth, J., Petersen, W., and Stanev, E. V.: Use of FerryBox surface temperature and salinity measurements to improve model based state estimates for the German Bight, J. Mar. Syst., 88, 45-59, doi:10.1016/j.jmarsys.2011.02.020, 2011.

Gurgel, K.-W., Antonischki, G., Essen, H.-H., and Schlick, T.: Wellen Radar (WERA): A new ground-wave based HF radar for ocean remote sensing, Coast. Eng., 37, 219-234, 1999.

Günther, H., Hasselmann, S. and Janssen, P. A. E. M.: The WAM model cycle 4, Report Deutsches Klimarechenzentrum, DKRZTR-4, 26, 1, 1992.

Haller, M., Janssen, F., Siddorn, J., Petersen, W., and Dick, S.: Evaluation of numerical models by FerryBox and fixed platform in situ data in the southern North Sea, Ocean Sci., 11, 879-896, doi:10.5194/os-11-879-2015, 2015.

Hegseth, E. N. and Tverberg, V.: Effect of Atlantic water inflow on timing of the phytoplankton spring bloom in a high Arctic 
fjord (Kongsfjorden, Svalbard), J. Mar. Syst., 113-114, 94-105, doi:10.1016/j.jmarsys.2013.01.003, 2013.

Helmholz, H., Lassen, S., Ruhnau, C., Pröfrock, D., Erbslöh, H.-B., and Prange, A.: Investigation on the proteome response of transplanted Blue mussel (Mytilus sp.) during a long term exposure experiment at differently impacted field stations in the German Bight (North Sea), Mar. Environ. Res., 110, 69-80, 2015.

Hodapp, D., Meier, S., Muijsers, F., Badewien, T. H., and Hillebrand, H.: Structural equation modeling approach to the diversity-productivity relationship of Wadden Sea phytoplankton, Mar. Ecol.-Progr. Ser., 523, 31-40, doi:10.3354/meps11153, 2015.

Holinde, L., Badewien, T. H., Freund, J. A., Stanev, E. V., and Zielinski, O.: Processing of water level derived from water pressure data at the Time Series Station Spiekeroog, Earth Syst. Sci. Data, 7, 289-297, doi:10.5194/essd-7-289-2015, 2015.

Hofmeister, R., Flöser, G., and Schartau, M.: Estuarine circulation sustains horizontal nutrient gradients in freshwater-influenced coastal systems, Geo-Marine Letters, under revision, 2017.

Hop, H., Pearson, T., Hegseth, E. N., Kovacs, K. M., Wiencke, C., Kwasniewski, S., Eiane, K., Mehlum, F., Gulliksen, B., Wlodarska-Kowalczuk, M., Lydersen, C., Weslawski, J. M., and Cochrane, S.: The marine ecosystem of Kongsfjorden, Svalbard, Polar Res., 21, 167-208, doi:10.1111/j.17518369.2002.tb00073.x, 2002.

Hop, H., Wiencke, C., Vögele, B., and Kovaltchouk, N. A.: Species composition, zonation, and biomass of marine benthic macroalgae in Kongsfjorden, Svalbard, Bot. Mar., 55, 399-414, doi:10.1515/bot-2012-0097, 2012.

Howarth, M. J.: North Sea circulation, Encyclopedia of Ocean Sciences, 1, 1912-1921, 2001.

Intergovernmental Oceanographic Commission (of UNESCO): The Case for GOOS. Report of the IOC Blue Ribbon Panel for a Global Ocean Observing System (GOOS), IOC/INF-915, Paris, 62, 27 January 1993.

Intergovernmental Oceanographic Commission: GOOS Coastal Module Planning Workshop Report, Scientific Committee on Oceanic Research of ICSU for J-GOOS, Workshop Report No. 131, GOOS No. 35, Miami, 57, 24-28 February 1997.

IPCC: Climate Change 2014: Synthesis Report, Contribution of Working Groups I, II and III to the Fifth Assessment Report of the Intergovernmental Panel on Climate Change, Core Writing Team, edited by: Pachauri, R. K. and Meyer, L. A., IPCC, Geneva, Switzerland, 151 pp., 2014.

Janssen, F., Färber, P., Huettel, M., Meyer, V., and Witte, U.: Porewater advection and solute fluxes in permeable marine sediments (I): Calibration and performance of the novel benthic chamber system Sandy, Limnol. Oceanogr., 50, 768-778, 2005.

Jones, C., Creed, E., Glenn, S., Kerfoot, J., Kohut, J., Mudgal, C., and Schofield, O.: Slocum gliders - a component of operational oceanography, Proc. UUST, Autonomous Undersea Systems Institute, 2005.

Kays, R., Crofoot, M. C., Jetz, W., and Wikelski, M.: Terrestrial animal tracking as an eye on life and planet, Science, 348, aaa2478, doi:10.1126/science.aaa2478, 2015.

Kirk, J. T. O.: Point-source integrating-cavity absorption meter: theoretical principles and numerical modeling, Appl. Opt., 36, 6123-6128, doi:10.1364/AO.36.006123, 1997.
Komen, G. J., Cavaleri, L., Donelan, M., Hasselmann, K., Hasselmann, S., and Janssen, P.: Dynamics and Modelling of Ocean Waves, Cambridge University Press, Cambridge, UK, 560, 1994.

Koschinsky, S., Culik, B., Henriksen, O. D., Tregenza, N., Ellis, G., Jansen, C., and Kathe, G.: Behavioral reactions of freeranging porpoises and seals to the noise of a simulated $2 \mathrm{MW}$ windpower generator, Mar. Ecol.-Progr. Ser., 265, 263-273, doi:10.3354/meps265263, 2003.

Kwoll, E., Winter, C., and Becker, M.: Intermittent suspension and transport of fine sediment over natural tidal bedforms, in: Coherent Structures in Flows at the Earth's Surface, edited by: Venditti, J. G., Best, J., Church, M. and Hardy, R. J., Wiley-Blackwell, London, doi:10.1002/9781118527221.ch15, 2013.

Kwoll, E., Becker, M., and Winter, C.: With or against the tide: the influence of bedform asymmetry on the formation of macroturbulence and suspended sediment patterns, Water Resour. Res., 50, 1-16, doi:10.1002/2013WR014292, 2014.

Krämer, K. and Winter, C.: Predicted ripple dimensions in relation to the precision of in situ measurements in the southern North Sea, Ocean Sci., 12, 1221-1235, doi:10.5194/os-12-1221-2016, 2016.

Lass, H. U., Mohrholz, V., Knoll, M., and Prandke, H.: Enhanced Mixing Downstream of a Pile in an Estuarine Flow, J. Mar. Syst., 74, 505-527, doi:10.1016/j.jmarsys.2008.04.003, 2008.

Lee, Z. P., Carder, K. L., Steward, R. G., Peacock, T. G., Davis, C. O., and Patch, J. S.: An Empirical Algorithm for Light Absorption by Ocean Water Based on Colour, J. Geophys. Res.-Oceans, 103, 27967-27978, doi:10.1029/98JC01946, 1998.

Lennartz, S. T., Lehmann, A., Herrford, J., Malien, F., Hansen, H.P., Biester, H., and Bange, H. W.: Long-term trends at the Boknis Eck time series station (Baltic Sea), 1957-2013: does climate change counteract the decline in eutrophication?, Biogeosciences, 11, 6323-6339, doi:10.5194/bg-11-6323-2014, 2014.

Lerebourg, C. J. Y., Pilgrim, D. A., Ludbrook, G. D., and Neal, R.: Development of a point source integrating cavity absorption meter, J. Opt. A Pure Appl. Opt., 4, 4 S56-S65, 2002.

Lettmann, K. A., Wolff, J. O., and Badewien, T. H.: Modeling the impact of wind and waves on suspended particulate matter fluxes in the East Frisian Wadden Sea (southern North Sea), Ocean Dynam., 59, 239-262, doi:10.1007/S10236-009-0194-5, 2009.

Loewe, P. (Ed.): System Nordsee - Zustand 2005 im Kontext langzeitlicher Entwicklungen, Berichte des BSH, 44, Bundesamt für Seeschifffahrt und Hydrographie, Hamburg und Rostock, 270, 2009.

Lorkowski, I., Paetsch, J., Moll, A., and Kuehn, W.: Interannual variability of carbon fluxes in the North Sea from 1970 to 2006 - competing effects of abiotic and biotic drivers on the gas exchange of $\mathrm{CO}_{2}$, Estuarine, Coastal and Shelf Science 100, 38-57, doi:10.1016/j.ecss.2011.11.037, 2012.

Ludewig, E.: On the Effect of Offshore Wind Farms on the Atmosphere and Ocean Dynamics, Hamburg Studies on Maritime Affairs 31, Springer International Publishing Switzerland, doi:10.1007/978-3-319-08641-5_1, 2015 ISBN: 978-3319-08640-8 (Print) 978-3-319-08641-5, 2015.

Maerz, J., Hofmeister, R., van der Lee, E. M., Gräwe, U., Riethmüller, R., and Wirtz, K. W.: Maximum sinking velocities of suspended particulate matter in a coastal transition zone, Biogeosciences, 13, 4863-4876, doi:10.5194/bg-13-4863-2016, 2016. 
Maresca, S., Braca, P., Horstmann, J., and Grasso, R.: Maritime surveillance using multiple high-frequency surface-wave radars, IEEE T. Geosci. Remote, 52, 5056-5071, 2014.

Meier, S., Muijsers, F., Beck, M., Badewien, T. H., and Hillebrand, H.: Dominance of the non-indigenous diatom Mediopyxis helysia in Wadden Sea phytoplankton can be linked to broad tolerance to different Si and N supplies, J. Sea. Res., 95, 36-44, doi:10.1016/J.Seares.2014.10.001, 2015.

Merckelbach, L.: On the probability of underwater glider loss due to collision with a ship, J. Mar. Sci. Techonol., 18, 75-86, doi:10.1007/s00773-012-0189-7, 2013.

Merckelbach, L.: Depth-averaged instantaneous currents in a tidally dominated shelf sea from glider observations, Biogeosciences, 13, 6637-6649, doi:10.5194/bg-13-6637-2016, 2016.

Metfies, K., Schroeder, F., Hessel, J., Wollschläger, J., Micheller, S., Wolf, C., Kilias, E., Sprong, P., Neuhaus, S., Frickenhaus, S., and Petersen, W.: High-resolution monitoring of marine protists based on an observation strategy integrating automated on-board filtration and molecular analyses, Ocean Sci., 12, 1237-1247, doi:10.5194/os-12-1237-2016, 2016.

Moore, C., Barnand, A., Fietzek, P., Lewis, M., Sosik, H., White, S., and Zielinski, O.: Optical tools for ocean monitoring and research, Ocean Sci., 5, 661-684, doi:10.5194/os-5-661-2009, 2009.

Neumann, A., Friedrich, J., van Beusekom, J. E. E., and Naderipour, C.: Spatial and temporal patterns in oxygen and nutrient fluxes in sediment of German Bight (North Sea), EGU 2016-14238, 2016.

North, R. P., Riethmüller, R., and Baschek, B.: Detecting small-scale horizontal gradients in the upper ocean using wavelet analysis, Estuarine, Coast. Shelf Sci., 180, 221-229, doi:10.1016/j.ecss.2016.06.031, 2016.

NOSCCA: North Sea Climate Change Assessment, edited by: Quante, M. and Colijn, F., Springer, 528 pp., doi:10.1007/9783-319-39745-0, 2016.

Oehmcke, S., Zielinski, O., and Kramer, O.: Event detection in marine time series data. Proceedings of KI 2015: Advances in Artifical Intelligence, Lecture Notes Comp. Sci., 9324, 279-286, doi:10.1007/978-3-319-24489-1_24, 2015.

Onken, R. and Riethmüller, R.: Determination of the freshwater budget of tidal flats from measurements near a tidal inlet, Cont. Shelf Res., 30, 924-933, doi:10.1016/j.csr.2010.02.004, 2010.

Onken, R., Callies, U., Vaessen, B., and Riethmüller, R.: Indirect determination of the heat budget of tidal flats, Cont. Shelf Res., 27, 1656-1676, doi:10.1016/j.csr.2007.01.029, 2007.

Onken, R., Garbe, H., Schröder, S., and Janik, M.: A new instrument for sediment temperature measurements, J. Mar. Sci. Technol., 15, 427-433, doi:10.1007/s00773-010-0096-8, 2010.

Oehler, T., Martinez, R., Schückel, U., Winter, C., Kröncke, I., and Schlüter, M.: Seasonal and spatial variations of benthic oxygen and nitrogen fluxes in the Helgoland Mud Area (southern North Sea), Cont. Shelf Res., 106, 118-129, doi:10.1016/j.csr.2015.06.009, 2015a.

Oehler, T., Schlüter, M., and Schückel, U.: Seasonal dynamics of the biogenic silica cycle in surface sediments of the Helgoland Mud Area (southern North Sea), Cont. Shelf Res., 107, 103-114, doi:10.1016/j.csr.2015.07.016, 2015b.

Örek, H., Doerffer, R., Röttgers, R., Boersma, M., and Wiltshire, K. H.: Contribution to a bio-optical model for remote sensing of Lena River water, Biogeosciences, 10, 7081-7094, doi:10.5194/bg-10-7081-2013, 2013.

OSPAR: Second OSPAR Integrated Report on the Eutrophication Status of the OSPAR Maritime Area, OSPAR Commission, 2008.

Otto, L., Zimmerman, J. T. F., Furnes, G. K., Mork, M., Saetre, R., and Becker, G.: Review of the physical oceanography of the North Sea, Netherlands, J. Sea Res., 26, 161-238, 1990.

Petersen, J., Pröfrock, D., Paschke, A., Broekaert, J. A. C., and Prange, A.: Laboratory calibration and field testing of the Chemcatcher Metal for trace levels of rare earth elements in estuarine waters, Environ. Sci. Water Res. Technol., 22, 16051-16059, doi:10.1007/s11356-015-4823-x, 2015a.

Petersen, J., Pröfrock, D., Paschke, A., Langhans, V., Broekaert, J. A. C., and Prange, A.: Development and field test of a mobile continuous flow system utilizing Chemcatcher for monitoring of rare earth elements in marine environments, Environ. Sci. Water Res. Technol., doi:10.1039/c5ew00126a, 2015b.

Petersen, W.: FerryBox Systems: State-of-the-Art in Europe and Future Development, J. Mar. Syst., 140A, 4-12, doi:10.1016/j.jmarsys.2014.07.003, 2014.

Petersen, W., Schroeder, F., and Bockelmann, F.-D.: FerryBox - Application of continuous water quality observations along transects in the North Sea, Ocean Dynam., 61, 1541-1554, doi:10.1007/s10236-011-0445-0, 2011.

Postma, H.: Introduction to the symposium on organic matter in the Wadden Sea, Neth. Inst. Sea Res. Publ. Ser., 10, 15-22, 1984.

Reuter, R., Badewien, T. H., Bartholoma, A., Braun, A., Lübben, A., and Rullkötter, J.: A hydrographic time series station in the Wadden Sea (southern North Sea), Ocean Dynam., 59, 195-211, doi:10.1007/S10236-009-0196-3, 2009.

Riegman, R. and Colijn, F.: Evaluation of measurements and calculation of primary production in the Doggerbank area (North Sea) in summer 1988, Mar. Ecol.-Progr. Ser., 69, 125-132, 1991.

Robinson, I. S.: Measuring the oceans from space: the principles and methods of satellite oceanography, Berlin, Germany, Springer/Praxis Publishing, 669, 2004.

Röttgers, R., Schönfeld, W., Kipp, P. R., and Doerffer, R.: Practical test of a point-source integrating cavity absorption meter: the performance of different collector assemblies, Appl. Opt., 44, 5549-5560, doi:10.1364/AO.44.005549, 2005.

Rullkötter, J.: The back-barrier tidal flats in the southern North Sea - a multidisciplinary approach to reveal the main driving forces shaping the system, Ocean Dynam., 59, 157-165, 2009.

Schaap, D. and Lowry, R. K.: SeaDataNet-Pan-European Infrastructure for Marine and Ocean Data Management: Unified Access to Distributed Data Sets, Int. J. Digital Earth, 3, S1, 50-69, doi:10.1080/17538941003660974, 2010.

Schulz, A. C., Badewien, T. H., and Zielinski, O.: Impact of currents and turbulence on turbidity dynamics at the time series station Spiekeroog (Wadden Sea, Southern North Sea). Current, waves and turbulence measurement (CWTM), 11th IEEE/OES, 2015, doi:10.1109/CWTM.2015.7098095, 2015.

Schulz, J.: The geometric optics of subsea imaging. Invited chapter for the book "Subsea optics and imaging", Woodhead Publishing, Editors: Watson and Zielinski, doi:10.1533/9780857093523.3.243, 2013.

Schulz, J., Barz, K., Ayon, P., Lüdtke, A., Zielinski, O., Mengedoht, D., and Hirche, H.-J.: Imaging of plankton specimens with the Lightframe On-sight Keyspecies Investigation (LOKI) sys- 
tem, Journal of the European Optical Society - Rapid publications 10017s, doi:10.2971/jeos.2010.10017s, 2010.

Schulz, M., von Beusekom, J., Bigalke, K., Brockmann, U. H., Dannecker, W., Gerwig, H., Grassl, H., Lenz, C.-J., Michaelsen, K., Niemeier, U., Nitz, T., Plate, E., Pohlmann, T., Raabe, T., Rebers, A., Reinhardt, V., Schatzmann, M., Schlünzen, K. H., Schmidt-Nia, R., Stahlschmidt, T., Steinhoff, G., and von Salzen, K.: The atmospheric impact on fluxes of nitrogen, POPs and energy in the German Bight, German J. Hydrogr., 51, 133-154, doi:10.1007/BF02764172, 1999.

Schrum, C., Alekseeva, I., and St. John, M.: Development of a coupled physical-biological ecosystem model ECOSMO: part I: model description and validation for the North Sea, J. Mar. Syst., 61.1, 79-99, 2006.

SCOR Working Group 75: Methodology for oceanic $\mathrm{CO}_{2}$ measurements, UNESCO technical papers in marine science, 65,44 , 1988.

SeaDataNet: Standards for Data Quality Control, available at: https: //www.seadatanet.org/Standards (last access: May 2017), 2010.

Stanev, E. V., Schulz-Stellenfleth, J., Staneva, J., Grayek, S., Seemann, J., and Petersen, W.: Coastal observing and forecasting system for the German Bight - estimates of hydrophysical states, Ocean Sci., 7, 569-583, doi:10.5194/os-7-569-2011, 2011.

Stanev, E. V., Ziemer, F., Schulz-Stellenfleth, J., Seemann, J., Staneva, J., and Gurgel, K. W.: Blending Surface Currents from HF Radar Observations and Numerical Modelling: Tidal Hindcasts and Forecasts, J. Atmos. Ocean Techn., 32, 256-281, doi:10.1175/JTECH-D-13-00164.1, 2015.

Stanev, E. V., Schulz-Stellenfleth, J., Staneva, J., Grayek, S., Grashorn, S., Behrens, A., Koch, W., and Pein, J.: Ocean forecasting for the German Bight: from regional to coastal scales, Ocean Sci., 12, 1105-1136, doi:10.5194/os-12-1105-2016, 2016.

Staneva, J., Stanev, E. V., Wolff, J. O., Badewien, T. H., Reuter, R., Flemming, B., Bartholoma, A., and Bolding, K.: Hydroynamics and sediment dynamics in the German Bight. A focus on observations and numerical modelling in the East Frisian Wadden Sea, Cont. Shelf Res., 29, 302-319, doi:10.1016/J.Csr.2008.01.006, 2009.

Staneva, J., Behrens, A., and Groll, N.: Recent Advances in Wave Modelling for the North Sea and German Bight, Die Küste, 81, 1-586, 2014.

Stempniewicz, L., Błachowiak-Samołyk, K., and Wesławski, J. M.: Impact of climate change on zooplankton communities, seabird populations and arctic terrestrial ecosystem-A scenario, DeepSea Res. Pt. II, 54, 2934-2945, doi:10.1016/j.dsr2.2007.08.012, 2007.

Stroeve, J., Holland, M. M., Meier, W., Scambos, T., and Serreze, M.: Arctic sea ice decline: Faster than forecast, Geophys. Res. Lett., 34, L09501, doi:10.1029/2007GL029703, 2007.

Su, J., Tian, T., Krasemann, H., Schartau, M., and Wirtz, K.: Response patterns of phytoplankton growth to variations in resuspension in the German Bight revealed by daily MERIS data in 2003 and 2004, Oceanologia, 57, 328-341, doi:10.1016/j.oceano.2015.06.001, 2015.

Sündermann, J., Hesse, K.-J., and Beddig, S.: Coastal mass and energy fluxes in the southeastern North Sea, German J. Hydrogr., 51, 113-132, doi:10.1007/BF02764171, 1999.

Svendsen, H., Beszczynska-Møller, A., Hagen, J. O., Lefauconnier, B., Tverberg, V., Gerland, S., Ørbæk, J. B., Bischof, K., Papucci,
C., Zajaczkowski, M., Azzolini, R., Bruland, O., and Wiencke, C.: The physical environment of Kongsfjorden/Krossfjorden, an Arctic fjord system in Svalbard, Polar Res., 21, 133-166, doi:10.1111/j.1751-8369.2002.tb00072.x, 2002.

Testor, P., Meyers, G., Pattiaratchi, C., Bachmayer, R., Hayes, D., Pouliquen, S., de la Villeon, L. P., Carval, T., Ganachaud, A., Gourdeau, L., Mortier, L., Claustre, H., Taillandier, V., Lherminier, P., Terre, T., Visbeck, M., Krahman, G., Karstensen, J., Alvarez, A., Rixen, M., Poulain, P., Osterhus, S., Tintore, J., Ruiz, S., Garau, B., Smeed, D., Griffiths, G., Merckelbach, L., Sherwin, T., Schmid, C., Barth, J., Schofield, O., Glenn, S., Kohut, J., Perry, M., Eriksen, C., Send, U., Davis, R., Rudnick, D., Sherman, J., Jones, C., Webb, D., Lee, C., Owens, B., and Fratantoni, D.: Gliders as a component of future observing systems, OceanObs'09: Sustained Ocean Observations and Information for Society, edited by: Hall, J., Harrison, D., and Stammer, D., 2 of OceansObs'09, Venice, Italy, eSA Publication WPP-306, doi:10.5270/OceanObs09.cwp.89, 2010.

UNESCO: Determination of chlorophyll in seawater: Report of intercalibration tests, UNESCO technical papers in marine science $35,21,1980$.

van Beusekom, J. E. E. and de Jonge, V. N.: Long-term changes in Wadden Sea nutrient cycles: importance of organic matter import from the North Sea, Hydrobiol., 475/476, 185-194, doi:10.1023/A:1020361124656, 2002.

van Beusekom, J. E. E., Brockmann, U. H., Hesse, K.-J., Nickel, W., Pormeba, K., and Tillmann, U.: The importance of sediments in the transformation and turnover of nutrients and organic matter in the Wadden Sea and German Bight, German J. Hydrogr., 51, 245-266, doi:10.1007/BF02764176, 1999.

van Beusekom, J. E. E., Buschbaum, C., and Reise, K.: Wadden Sea tidal basins and the mediating role of the North Sea in ecological processes: scaling up of management?, Ocean Coast. Manage., 68, 69-78, doi:10.1016/j.ocecoaman.2012.05.002, 2012.

van De Poll, W. H., Maat, D. S., Fischer, P., Rozema, P. D., Daly, O. B., Koppelle, S., Visser, R. J. W., and Buma, A. G. J.: Atlantic Advection Driven Changes in Glacial Meltwater: Effects on Phytoplankton Chlorophyll-a and Taxonomic Composition in Kongsfjorden, Spitsbergen, Front. Mar. Sci., 3, 60, doi:10.3389/fmars.2016.00200, 2016.

van Leeuwen, S. M., van der Molen, J., Ruardij, P., Fernand, L., and Jickells, T.: Modelling the contribution of deep chlorophyll maxima to annual primary production in the North Sea, Biogeochemistry, 113, 137-152, 2013.

Vivone, G., Braca, P., and Horstmann, J.: KnowledgeBased Multi-Target Ship Tracking for HF Surface Wave Radar Systems, IEEE T. Geosci. Remote, 53, 3931-3949, doi:10.1109/TGRS.2014.2388355, 2015.

Voynova, Y. G., Brix, H., Petersen, W., Weigelt-Krenz, S., and Scharfe, M.: Extreme flood impact on estuarine and coastal biogeochemistry: the 2013 Elbe flood, Biogeosciences, 14, 541557, doi:10.5194/bg-14-541-2017, 2017.

Wahl, T., Haigh, I. D., Woodworth, P. L., Albrecht, F., Dillingh, D., Jensen, J., Nicholls, R. J., Weisse, R., and Wöppelmann, G.: Observed mean sea level changes around the North Sea coastline from 1800 to present, Earth-Sci. Rev., 124, 51-67, doi:10.1016/j.earscirev.2013.05.003, 2013.

Wehkamp, S. and Fischer, P.: Impact of hard-bottom substrata on the small-scale distribution of fish and decapods in shallow subti- 
dal temperate waters, Helgoland Mar. Res., doi:10.1007/s10152012-0304-5, hdl:10013/epic.39252, 2012.

Wehkamp, S. and Fischer, P.: The impact of coastal defence structures (tetrapods) on decapod crustaceans in the southern North Sea, Mar. Environ. Res., 92, 52-60, doi:10.1016/j.marenvres.2013.08.011, hdl:10013/epic.47436, $2013 \mathrm{a}$.

Wehkamp, S. and Fischer, P.: Impact of coastal defence structures (tetrapods) on a demersal hard-bottom fish community in the southern North Sea, Mar. Environ. Res., doi:10.1016/j.marenvres.2012.10.013, hdl:10013/epic.40445, 2013b.

Wehkamp, S. and Fischer, P.: A practical guide to the use of consumer-level digital still cameras for precise stereogrammetric in situ assessments in aquatic environments, Underw. Tech., 32, 111-128, doi:10.3723/ut.32.111, hdl:10013/epic.43817, 2014.

Willis, K., Cottier, F., Kwasniewski, S., Wold, A., and FalkPetersen, S.: The influence of advection on zooplankton community composition in an Arctic fjord (Kongsfjorden, Svalbard), J. Marine Syst., 61, 39-54, doi:10.1016/j.jmarsys.2005.11.013, 2006.

Wilson, R. P. and Vandenabeele, S. P.: Technological innovation in archival tags used in seabird research, Mar. Ecol.-Prog. Ser., 451, 245-262, doi:10.3354/meps09608, 2012.
Wirtz, K. and Kerimoglu, O.: Optimality and variable co-limitation controls autotrophic stoichiometry, Front. Mar. Sci., submitted, 2017.

Witte, U. and Pfannkuche, O.: High rates of benthic carbon remineralization in the abyssal Arabian Sea, Deep-Sea Res. Pt. II, 47, 2785-2804, doi:10.1016/S0967-0645(00)00049-7, 2000.

Wollschläger, J., Grunwald, M., Röttgers, R., and Petersen, W.: Flow-through PSICAM: a new approach for determining water constituents absorption continuously, Ocean Dynam., 63, 761775, doi:10.1007/s10236-013-0629-x, 2013.

Wollschläger, J., Röttgers, R., Petersen, W., and Wiltshire, K. H.: Performance of absorption coefficient measurements for the in situ determination of chlorophyll $a$ and total suspended matter, J. Exp. Mar. Biol. Ecol., 453, 138-147, doi:10.1016/j.jembe.2014.01.011, 2014.

Zielinski, O., Busch, J. A., Cembella, A. D., Daly, K. L., Engelbrektsson, J., Hannides, A. K., and Schmidt, H.: Detecting marine hazardous substances and organisms: sensors for pollutants, toxins, and pathogens, Ocean Sci., 5, 329-349, doi:10.5194/os5-329-2009, 2009.

Zielinski, O., Voss, D., Saworski, B., Fiedler, B., and Koertzinger, A.: Computation of nitrate concentrations in turbid coastal waters using an in situ ultraviolet spectrophotometer, J. Sea Res., 65, 456-460, 2011. 